\title{
Does the barnacle settlement pattern affect ship resistance and powering?
}

\author{
Dogancan Uzun $^{\mathrm{a}^{*}}$, Refik Ozyurt ${ }^{\mathrm{a}}$, Yigit Kemal Demirel ${ }^{\mathrm{a}}$, Osman Turan ${ }^{\mathrm{a}}$ \\ a Department of Naval Architecture, Ocean and Marine Engineering, University of \\ Strathclyde, 100 Montrose Street, Glasgow, G4 0LZ, UK \\ *corresponding author; e-mail: dogancan.uzun@strath.ac.uk, phone: +44(0)7933188524
}

\begin{abstract}
Predictions of increases in ship frictional resistance and powering were made for a range of barnacle fouling conditions. A series of towing tests were conducted using flat plates systematically covered with $3 \mathrm{D}$ printed barnacle tiles. The tests were set up to investigate the effect of barnacle settlement on the resistance and effective power of the ship. Therefore, a chaotic settlement which is called natural settlement, was designed to represent real barnacle settlement in nature. An extensive comparison was made between this natural settlement and the settlement that was designed in accordance with the standards. The drag coefficients and roughness functions values were determined and full-scale ship resistance and powering were estimated for six different ships at their cruise speed by using boundary layer similarity law. In addition, decreases in cruising speed due to barnacle fouling at fixed effective power were estimated as part of the case studies. The results indicate that settlement pattern caused up to $\sim 10.5 \%$ difference in frictional resistance and $\sim 6.7 \%$ difference in powering at cruise speeds whereas this settlement pattern caused up to $\sim 20.5 \%$ speed reduction at fixed effective power.
\end{abstract}




\section{INTRODUCTION}

Biofouling on ship hulls increases surface roughness, which in return causes increased ship frictional resistance and powering. Therefore, ship operators decide whether to increase power to keep agreed operation speed resulting in increased fuel oil consumption or reduce the speed at fixed engine power by delaying arrival time to the destination which may cause contractual penalties [1] [2]. Marine fouling-control coatings are prevalently used to smooth hull surfaces to reduce the frictional resistance and fuel consumption of a ship as well as to assist corrosion prevention [3].

The ship resistance is mainly composed of frictional and wave-making resistance. Frictional resistance, especially for low-speed ships, is the dominant component of ship total resistance. For instance, a tanker cruising at design speed uses the majority of its power for overcoming frictional resistance in calm water.

As the ship moves through the water, fluid particles right next to the ship hull stick to the ship hull (no-slip condition). Due to the interaction with fluid particles stuck to the hull, fluid particles just above the surface loses velocity. This effect gradually decreases and creates a thin layer (boundary layer) in which water flow velocity changes from zero to free stream velocity at a certain distance from the surface. Biofouling increases the roughness of the hull surface, which causes an increase in boundary layer thickness and frictional resistance of the hull.

There is a considerable amount of research in the literature on the effect of biofouling on ship frictional resistance which was conducted by means of various methods including towing flat plates, rotating disks and cylinders, water tunnels and ship trials.

McEntee [4] conducted the first extensive experimental study on the effects of biofouling on frictional resistance. The flat plates in length of 10 feet were immersed in the Chesapeake Bay for 12 months to determine the change in frictional resistance. Each month a plate was taken for testing at various velocities from 2 to 9 knots for fouled and cleaned conditions at the United States experimental model basin. This study indicated that plates that covered by small barnacles showed four times higher frictional resistance values compared to clean condition after 12 months of seawater exposure. Izubuchi [5] estimated the increase in frictional resistance coefficient due to biofouling through several ship trials on the destroyer Yudachi during one year. Although quantifying the effect of fouling was not precise at a satisfactory degree, tests indicated that frictional resistance of the ship doubled after 300 days.

Kempf [6] developed the roughness coefficients $\left(C_{k}\right)$ by conducting towing tests with an $87.7 \mathrm{~m}$ pontoon in various surface conditions. Once adding this coefficient into the resistance equation of a real ship to calculate the increase in frictional resistance of a fouled ship, it was observed that frictional resistance of fouled ship is about double that of the un-fouled vessel. Conn et al. [7] conducted a trial test through a ship hull which was allowed to be fouled for 40 days, over a speed range from 5 to 15 knots and results indicated 5\% increase in frictional resistance. Watanabe et al. [8] investigated the effects of the slime on frictional resistance and the separation of slime through experiments on concentric cylinders, a model ship, and a rotating disk. After extrapolating these results to actual ships, the increase in total resistance was estimated to be $\sim 10 \%$. 
Loeb et al. [9] conducted an experiment by using rotating discs in order to obtain the effect of biofilm on the frictional drag. The results of the study indicate that frictional resistance increased by $\sim 10-20 \%$. Lewthwaite et al. [10] obtained $25 \%$ and $83 \%$ increases in frictional resistance by using small Pitot tube for a $23 \mathrm{~m}$ tender vessel after $\sim 240$ and $\sim 600$ days, respectively. Haslbeck and Bohlander [11] conducted a series of laboratory tests and ship trials in order to understand the efficiency of antifouling coatings and to determine the biofilm effect on ship power and fuel consumption. The majority of the tested coatings in the laboratory showed an increase in frictional resistance to range from $10 \%$ to $19 \%$ at a ship speed of 25 knots. A $K N O X$ class frigate BREWTON, coated with an ablative antifouling paint, was exposed to seawater for 22 months duration in Pearl Harbor, Hawaii. Then, the frigate was tested in ship trials, and it was observed that clean hull showed $18 \%$ decrease in shaft power compare to that of the fouled hull.

Schultz and Swain [12] and Schultz [13] conducted experiments on non-coated flat plates by using laser Doppler velocimetry in a recirculating water tunnel. The results indicated that increases in frictional resistance due to slime films and algae formation were in a range from $33 \%$ to $187 \%$. Holm et al. [14] conducted an extensive series of rotating disk tests by using a friction disk machine to examine differences among fouling release coatings. The drag penalties due to micro fouling ranged from $9 \%$ to $29 \%$. Schultz [15] tested the efficiency of 5 different coatings over flat plates after $\sim 287$ days seawater exposure and fouling coverages on the surfaces were assessed in accordance with the ASTM D3623 [16]. Following this, experimentally observed roughness functions were used in Granville's similarity law procedure [17] and then the increases in frictional resistance coefficient $\left(\mathrm{C}_{\mathrm{F}}\right)$ were extrapolated for a $150 \mathrm{~m}$ plate representing midsized merchant ships as well as frigates and destroyers. Results indicated that percentage increases in $C_{F}$ at ship scale in fouled condition ranged from $50 \%$ to $217 \%$ at 12 knots. Swain [18] conducted both static and dynamic immersion tests for two different biocide-based and two silicone-based foul release paints. After $\sim 60$ days static immersion all test surfaces were fouled with various fouling types including slime, barnacle, encrusting bryozoans and tubeworms. Next, a dynamic test was conducted for 15 days by means of a rotating stirrer which rotates at a rotational speed of 60 $\mathrm{rpm}$. Then, fouled test surfaces were towed through a boat cruising at 25 knots, and existing fouling conditions were assessed in terms of frictional resistance.

A more recent study provides an extensive and chronological review about the progress of antifouling coatings considering their improvement at reducing frictional resistance as well as their type, working mechanisms, and distribution of applied coatings for various geographical regions [19].

Demirel et al. [20] proposed a systematic experimental and numerical study on barnacle fouling to classify fouling conditions such as coverage ratios and barnacle dimensions and to investigate the effect of these independent conditions on ship resistance and powering. First, widely-known barnacle species was scanned with a 3D scanner and then manufactured by means of a 3D printer. Then, barnacle samples were attached on flat plates and towed in the tank at various speeds. The increases in frictional resistance were then extrapolated for various lengths of ships by using Granville [17] similarity law scaling procedure as similarly conducted in the studies of Demirel et al. [21], Schultz et al. [22], Turan et al.[23], Demirel [24] and Uzun et al. [25]. 
Following this, Song et al. [26] used a Computational Fluid Dynamics (CFD) based resistance simulation model to predict the effect of barnacle fouling focussing on the resistance and wake characteristics of the full scale KRISO container ship (KCS) hull based on the roughness functions of Demirel et al. [20]. The results of CFD simulations were compared with the results obtained by using Granville similarity law analysis [17].

The barnacle settlement, designed in accordance with ASTM D6990-05 [27] in Demirel et al. [20] and Uzun et al. [25], led researchers to investigate the effect of barnacle settlement on frictional resistance if the barnacles are located chaotically aiming to simulate barnacle settlement in nature. To date, numerous studies have been conducted to assess the effect of various fouling presence on ship resistance and powering. Despite this interest, no one, to the best of authors' knowledge, has investigated the settlement effect of barnacle fouling on ship resistance and powering.

To fill this gap, chaotic barnacle settlement, which is called natural settlement (NS) was designed to represent barnacle settlement in nature. Then, an extensive series of towing test was conducted on flat plates covered with these natural settlement configurations for $10 \%$, $20 \%, 40 \%$, and $50 \%$ surface coverages. The roughness functions and increases in $\mathrm{C}_{\mathrm{F}}$ were determined, and ship frictional resistance and effective power were estimated for six different ships at their cruise speeds. In addition, percentage decreases in cruising speeds at fixed effective power were estimated for the same case studies.

In order to investigate the effect of barnacle settlement, an extensive comparison was made between mixed-type configurations, which were provided in Uzun et al. [25] and the configurations produced in this study. Furthermore, this study contributes to existing roughness functions data in the literature by producing roughness functions of barnacle fouling conditions.

This paper is organised as follows: The experimental facilities, 3D barnacle model details, and the method are given in Section 2. The results of frictional resistance coefficients, determination of roughness functions, uncertainty estimations, as well as the predictions on the frictional increase and effective power for full-scale ships are presented in Section 3. Finally, the results of the study are discussed in Section 4, along with the suggestions for further research.

\section{EXPERIMENTAL SETUP, MODEL DETAILS AND THE METHOD}

The experiments were carried out at the Kelvin Hydrodynamics Laboratory (KHL) of the University of Strathclyde. The KHL test tank has dimensions of $76 \mathrm{~m}$ in length, $4.6 \mathrm{~m}$ in breadth and $2.5 \mathrm{~m}$ in depth. The tank is equipped with a digitally-controlled towing carriage, state-of-the-art absorbing wavemaker, and a highly effective sloping beach. The carriage has a velocity range of $0-5 \mathrm{~ms}^{-1}$, which covers the velocity range from 1.5 to $3.6 \mathrm{~ms}^{-1}$ used in this experiment. The freshwater was used in the experiment wherein the temperature of the water was monitored in order to consider the effect of viscosity change in evaluating drag coefficients.

The flat plates used for the tests were manufactured using 304 stainless steel grade sheet stock, and Fig. 1 depicts the dimensions of the flat plates. The thickness of the flat plates is 5 
$\mathrm{mm}$. The leading edges of the plates were shaped to a radius of $2.5 \mathrm{~mm}$ while the trailing edge was kept sharp in order to mitigate the extra drag due to flow separation. The flatness of the plates and dimensions were checked by using a CNC machine.

This experiment was set up in the same way as the one proposed by Demirel et al. [20]. However, this time, in order to simulate real fouling growth process, three different barnacle models were used together on the same barnacle tiles. Moreover, the size of the barnacle tiles used in Uzun et al. [25] and Demirel et al. [20] were divided into four smaller tiles. This allows us to design a chaotic and spontaneous settlement which is called natural settlement in this study. Natural barnacle fouling was stimulated in a more realistic view through designing mixed sized barnacle configurations as well as considering settlement pattern of barnacles Once barnacles are modelled, the models were delivered to the $3 \mathrm{D}$ printer to be manufactured. Fig. 2 illustrates the used barnacle tile in the Uzun et al. [25] and also the barnacle tiles designed by resizing it for natural settlement configuration in this study.

This method represents a viable approach to test drag resistance of flat plates, covered by artificial barnacles in various size and coverage rates. Moreover, it is also useful for making comparisons between the configurations that have different settlement patterns but the same coverage rates.

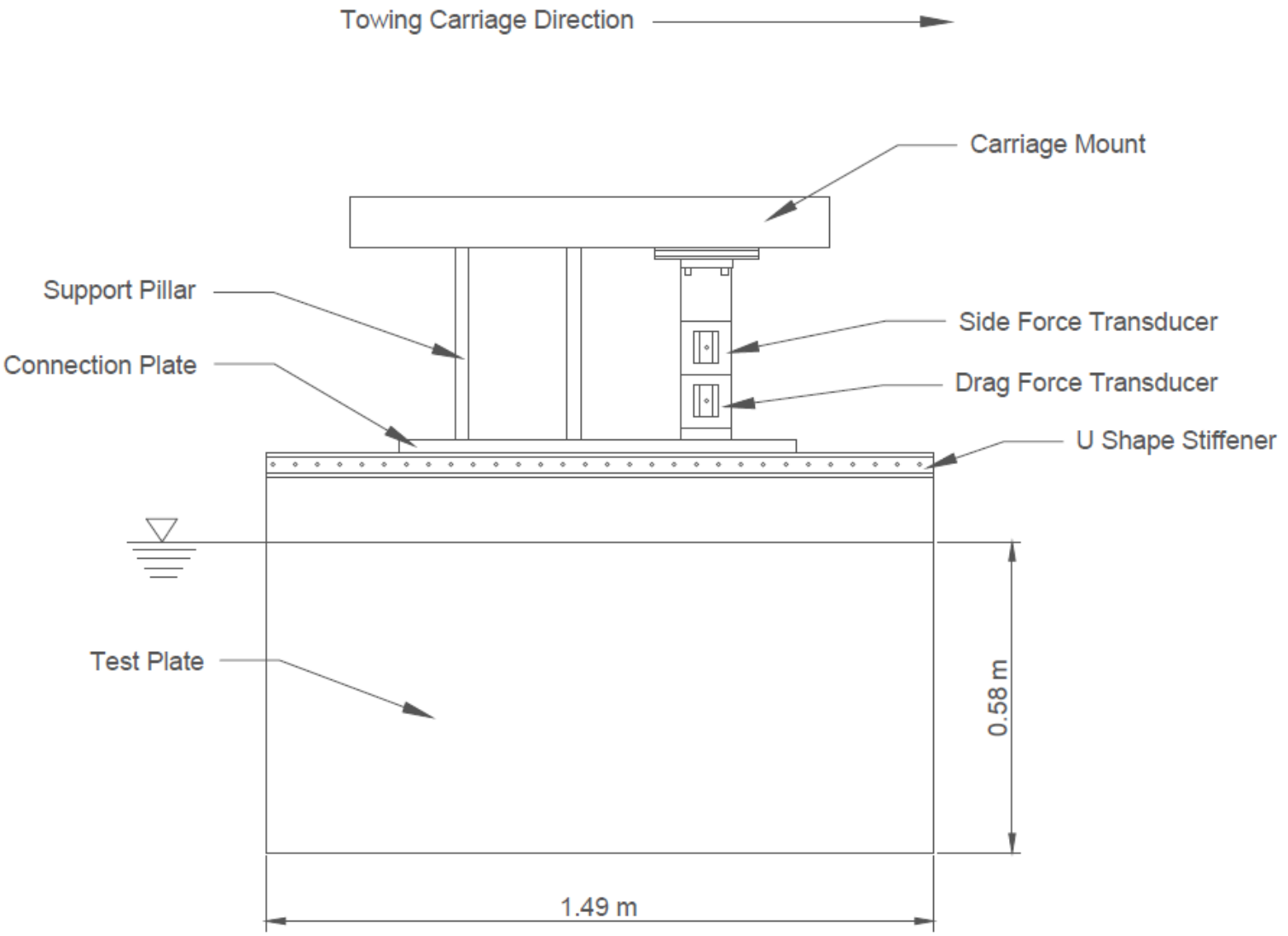

Fig. 1. Schematic of the flat plate test fixture

The artificial barnacles were glued onto the surfaces of the flat plates and then towing tests of the flat plates were conducted at a range of speeds of $1.5-3.6 \mathrm{~ms}^{-1}$. The same test setup, including test rig and alignment process in the studies of Demirel et al. [20] and Uzun et al. [25] was also used in this study as shown in Fig. 3. 


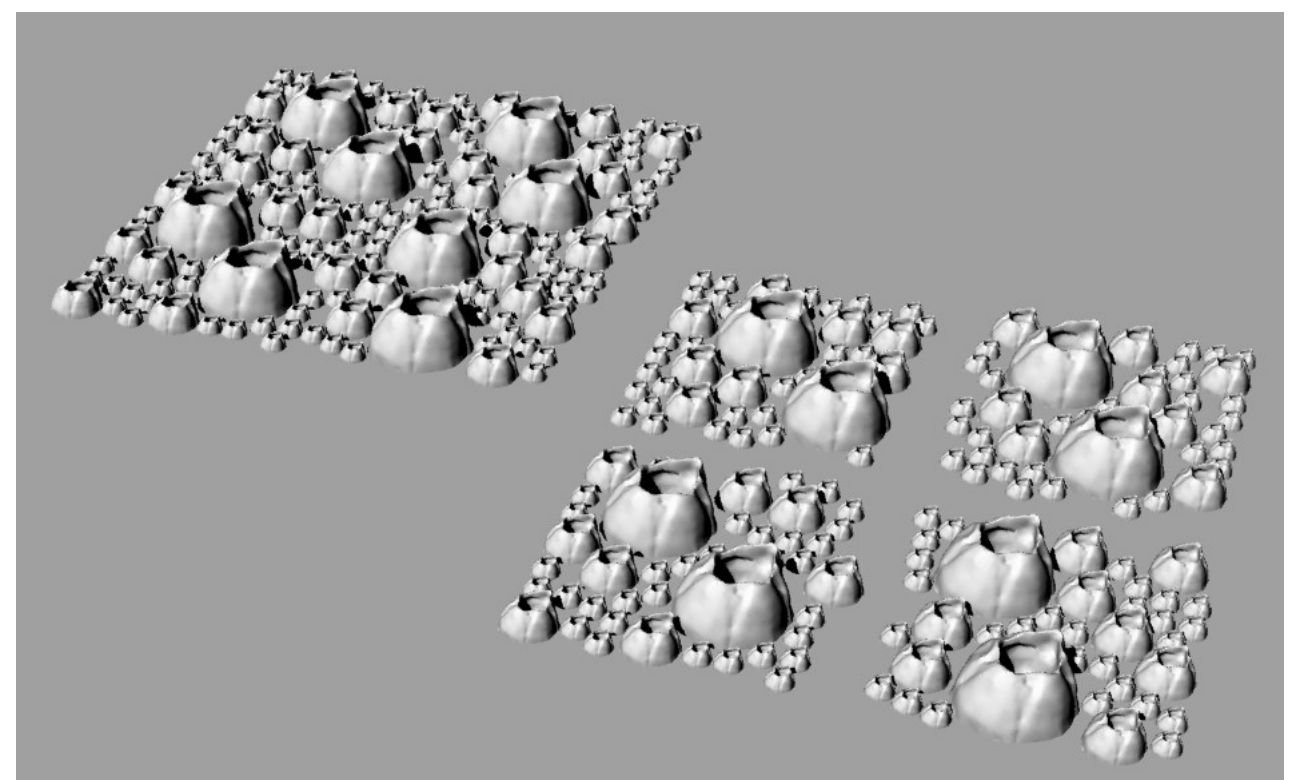

Fig. 2. 3D view of barnacle tiles for standard and natural settlement

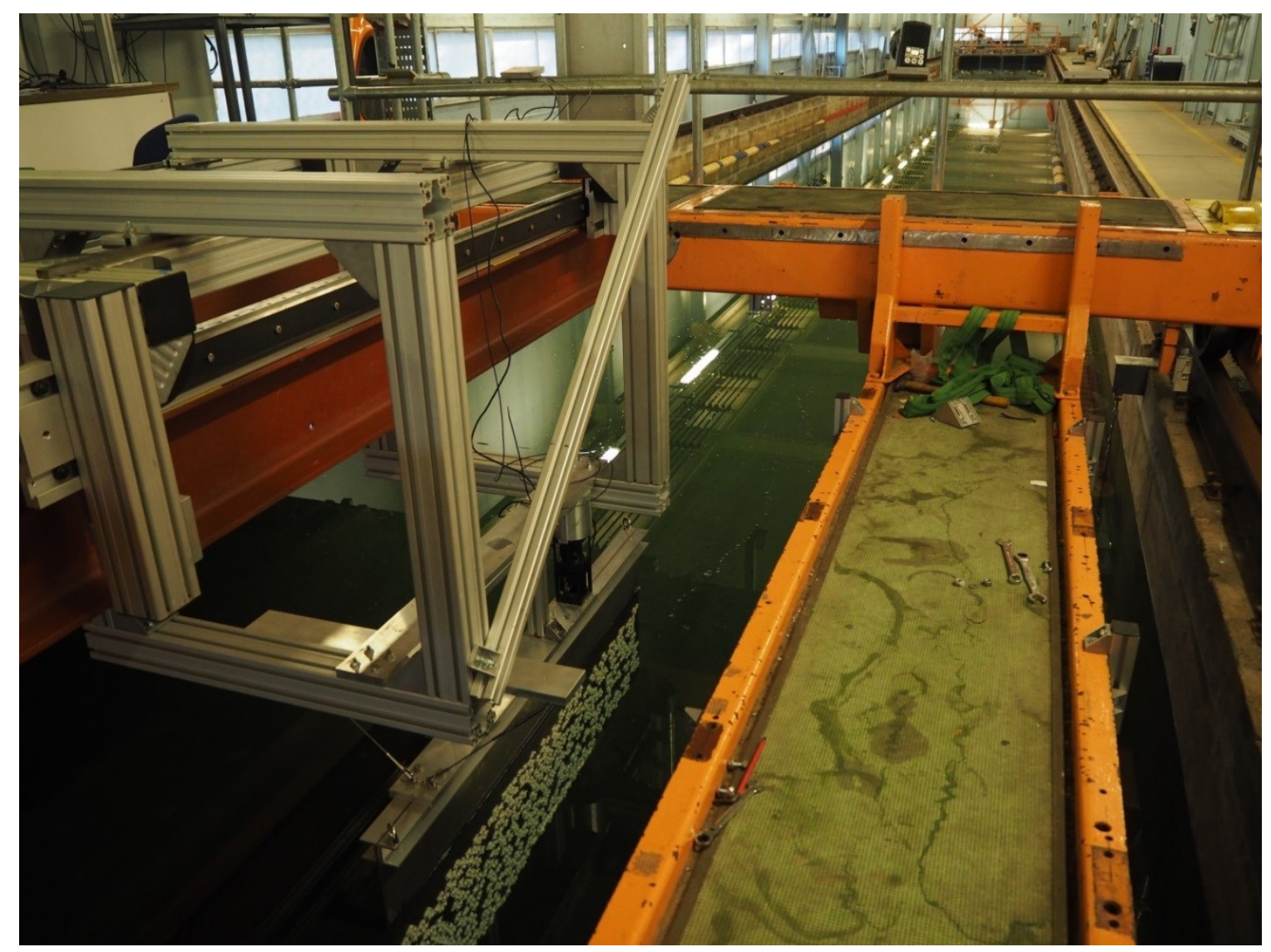

Fig. 3. Test set-up

Both towing force and side forces were measured via load cells during the experiment. The towing force was recorded for drag measurement whereas side forces were checked continuously to be sure that the plate is correctly aligned in the tank. The carriage speed was accurately measured using a digital encoder on a calibrated wheel. 
Four different surface coverage percentages and a bare plate representing the reference plate were considered as configurations of this experiment. Moreover, the biggest (B) type barnacle configurations (10\% B and 20\% B) measured in Demirel et al. [20] and mixed barnacle configurations (from $10 \%$ to $50 \%$ mixed) measured in Uzun et al. [20] were also included into the study in order to achieve the aim of this study. Dimensions of the B type barnacle configurations are $10 \mathrm{~mm}$ in diameter and $5 \mathrm{~mm}$ in height. On the other hand, mixed barnacle tiles include three different type barnacle configurations which are biggest $(10 \mathrm{~mm}$ in diameter \& $5 \mathrm{~mm}$ in height), medium (5mm in diameter \& $2.5 \mathrm{~mm}$ in height) and small (2.5 $\mathrm{mm}$ in diameter \& $1.25 \mathrm{~mm}$ height) type configurations. Table 1 summarises all configurations with the references of data.

Table 1 Configuration table showing the tests considered in the study

\begin{tabular}{|c|c|c|c|c|c|c|}
\hline \multirow{2}{*}{ Configuration } & Source & $\begin{array}{c}\text { Bare } \\
\text { Plate }\end{array}$ & $\begin{array}{c}10 \% \\
\text { SC }\end{array}$ & $\begin{array}{c}20 \% \\
\text { SC }\end{array}$ & $\begin{array}{c}40 \% \\
\text { SC }\end{array}$ & $\begin{array}{c}50 \% \\
\text { SC }\end{array}$ \\
\hline B & Demirel et al.[20] & $\mathrm{X}$ & $\mathrm{X}$ & $\mathrm{X}$ & & \\
\hline Mixed & Uzun et al. [25] & $\mathrm{X}$ & $\mathrm{X}$ & $\mathrm{X}$ & $\mathrm{X}$ & $\mathrm{X}$ \\
\hline NS Mixed & Present study & $\mathrm{X}$ & $\mathrm{X}$ & $\mathrm{X}$ & $\mathrm{X}$ & $\mathrm{X}$ \\
\hline
\end{tabular}

The main aim of this comparison between mixed configurations and NS mixed configurations is to get insight into the barnacle settlement effect on frictional resistance. Moreover, to the best of authors' knowledge, although several studies have been conducted in this area, this is the first study which investigates the settlement effect of barnacle fouling on frictional resistance through systematically conducted experiments.

In addition, roughness function behaviour of mixed type configurations was compared against the roughness function behaviour of the biggest type configuration in order to test the hypothesis proposes that largest roughness heights have the dominant influence on drag [15].

The experiment procedure and repeatability tests are explained in detail in Demirel et al. [20]. The settlement pattern was applied in line with the standards of ASTM-D6990-05 [27] except for the natural settlement configuration, which is designed by the authors for this study. 
ASTM settlement

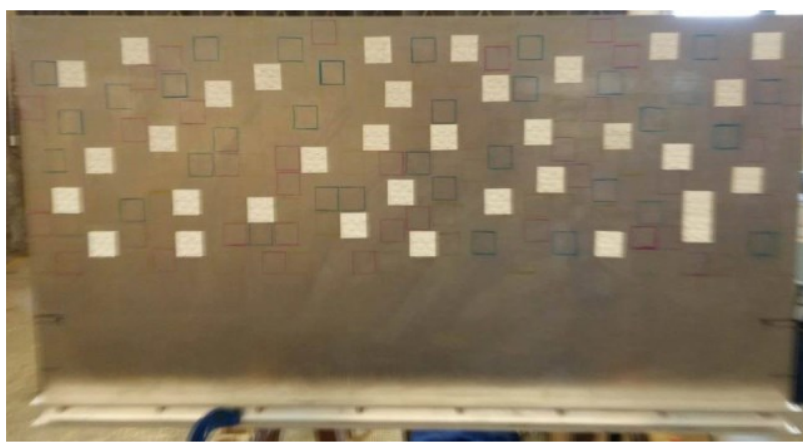

(a1)

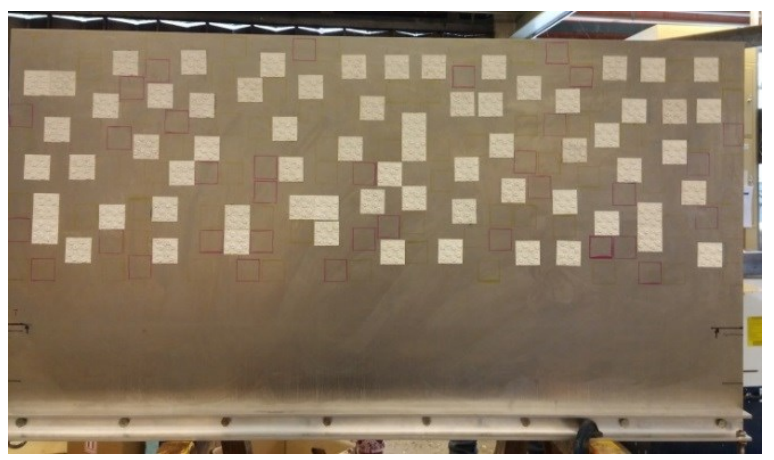

(b1)

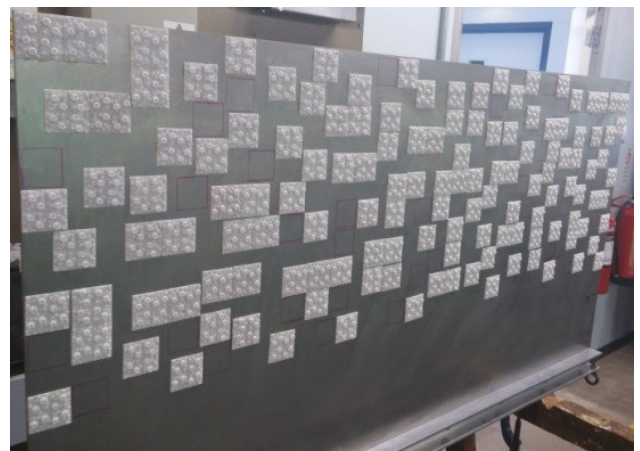

(c1)

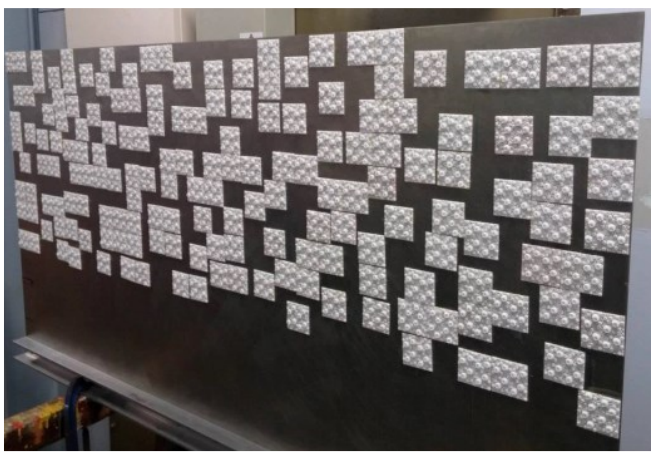

$(\mathrm{d} 1)$

\section{Proposed Natural Settlement}

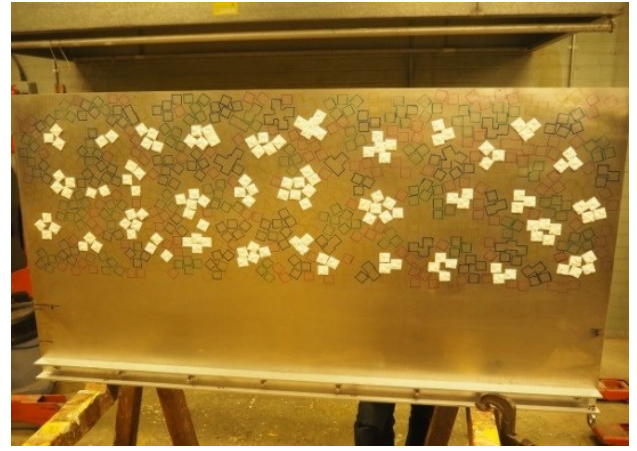

(a2)

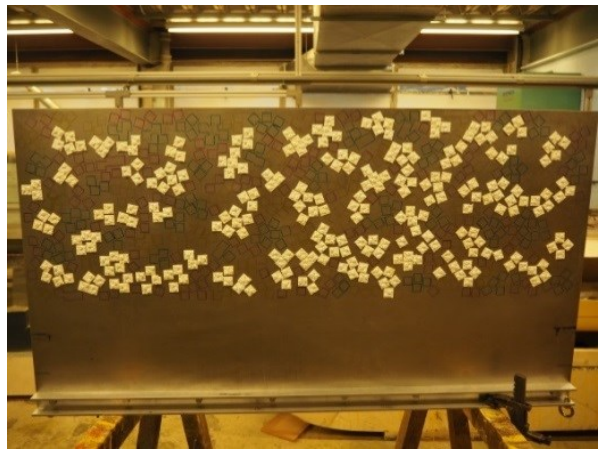

(b2)

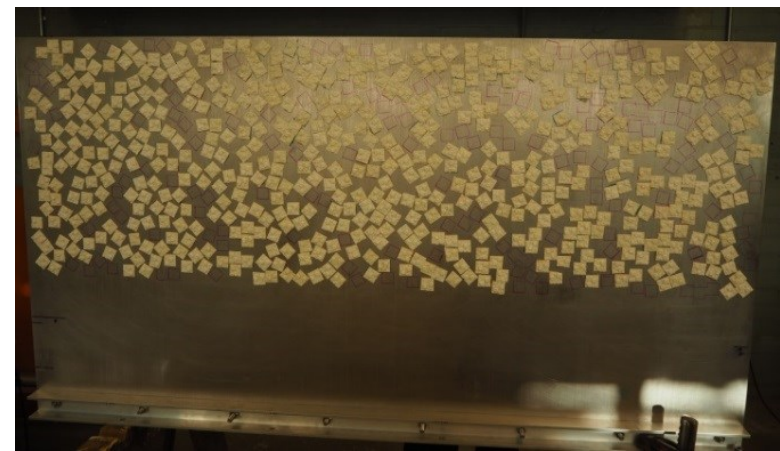

(c2)

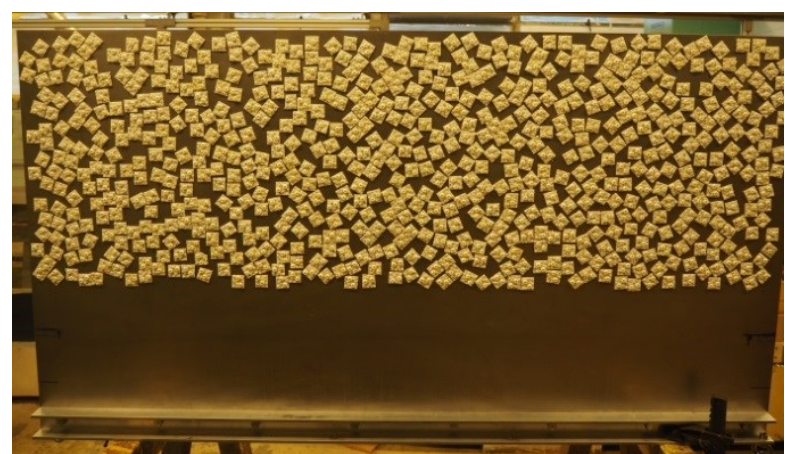

$(\mathrm{d} 2)$

Fig. 4. (a1) and (a2) 10\% Coverage; (b1) and (b2) 20\% Coverage; (c1) and (c2) 40\% Coverage; (d1) and (d2) 50\% Coverage 
Two sides of plate were covered symmetrically to minimize side forces as much as possible. Fig. 4. shows the configurations that were tested in accordance with ASTM D6990-05 [27] standards (a1,b1,c1,d1) taken from Demirel et al. [20] and those of which were designed by the authors to represent natural settlement $(\mathrm{a} 2, \mathrm{~b} 2, \mathrm{c} 2, \mathrm{~d} 2)$ for different coverage rates from $10 \%$ to $50 \%$.

Once the test results were obtained, as a first step, total drag coefficient $\left(\mathrm{C}_{T}\right)$ was calculated through general total drag equation as the density of water $(\rho)$, wetted surface area $(S)$ and speed $(V)$ are defined. Then, the Karman - Schoenherr equation [28] was employed to calculate the frictional resistance coefficient $\left(\mathrm{C}_{\mathrm{FS}}\right)$ of the reference plate (smooth plate). As $\mathrm{C}_{\mathrm{TS}}$ is composed of $\mathrm{C}_{\mathrm{FS}}$ and the residuary resistance coefficient $\left(\mathrm{C}_{\mathrm{R}}\right), \mathrm{C}_{\mathrm{RS}}$ can be obtained by subtracting $\mathrm{C}_{\mathrm{FS}}$ value from the $\mathrm{C}_{\mathrm{TS}}$ value of the reference plate. The calculated $\mathrm{C}_{\mathrm{RS}}$ value was taken as the $C_{R R}$ value of all test surfaces since the roughness has a negligible effect on the residuary resistance. [20]. Therefore, the $\mathrm{C}_{\mathrm{FS}}$ values calculated by Karman - Schoenherr equation represent frictional resistance coefficient in smooth condition whereas the $\mathrm{C}_{\mathrm{F}}$ values, which were calculated by subtracting the $C_{R}$ values from the $C_{T R}$ values for the rough conditions represent the $\mathrm{C}_{\mathrm{FR}}$. The mathematical expression for this is presented in Eq. 1,2 and 3.

$$
\begin{gathered}
C_{R_{S}}=C_{T_{S}}-C_{F_{S}} \\
C_{R_{S}}=C_{R_{R}} \\
C_{F_{R}}=C_{T_{R}}-C_{R_{R}}
\end{gathered}
$$

where subscript $\mathrm{S}$ indicates smooth condition, whereas subscript $\mathrm{R}$ indicates rough condition. The roughness Reynolds numbers, $k^{+}$, and roughness function values, $\Delta U^{+}$, were then evaluated by iteratively solving Eq. 4 and 5 by following the procedure of Granville [29]. After that, in order to investigate the roughness effect at full scale, evaluated values were then extrapolated to full-scale ships in various lengths at various ship speeds by using the in-house code developed for the similarity law scaling procedure of Granville [17]. All procedure can be found in detail in Demirel et al. [20] and Uzun et al. [25].

$$
\begin{gathered}
k^{+}=\left(\frac{k}{L}\right)\left(\frac{R e C_{F}}{2}\right)\left(\sqrt{\frac{2}{C_{F}}}\right)_{R}\left[1-\frac{1}{\kappa}\left(\sqrt{\frac{C_{F}}{2}}\right)_{R}+\frac{1}{\kappa}\left(\frac{3}{2 \kappa}-\Delta U^{+^{\prime}}\right)\left(\frac{C_{F}}{2}\right)_{R}\right] \\
\Delta U^{+}=\left(\sqrt{\frac{2}{C_{F}}}\right)_{S}-\left(\sqrt{\frac{2}{C_{F}}}\right)_{R}-19.7\left[\left(\sqrt{\frac{C_{F}}{2}}\right)_{S}-\left(\sqrt{\frac{C_{F}}{2}}\right)_{R}\right]-\frac{1}{\kappa} \Delta U^{+^{\prime}}\left(\sqrt{\frac{C_{F}}{2}}\right)_{R}
\end{gathered}
$$


where $\kappa$ is von Karman constant which is equal to $0.41, \mathrm{~L}$ is the plate length, $\mathrm{Re}$ is the Reynolds number, $\mathrm{C}_{\mathrm{F}}$ is the frictional drag coefficient, and $\Delta \mathrm{U}^{+^{\prime}}$ is the roughness function slope, which is the slope of $\Delta \mathrm{U}^{+}$as a function of $\ln \left(k^{+}\right)$. As stated by Granville for the same value of $\left(\operatorname{Re} \mathrm{C}_{\mathrm{F}}\right)$ the difference between $\left(\sqrt{\frac{2}{C_{F}}}\right)_{S}$ and $\left(\sqrt{\frac{2}{C_{F}}}\right)_{R}$ is approximately equal to $\Delta \mathrm{U}^{+}$ when it is plotted against $\log \left(\operatorname{Re} \mathrm{C}_{\mathrm{F}}\right)$.

The direct effect of biofouling on ships is the increased total resistance of ships, which means increased required effective power [30], to maintain the ship speed. In this case, there are two options available; either the operator reduces ship speed (speed reduction) or unintentional increase in power as well as fuel consumption to keep the ship at cruise speed. Eq. 6 was used to calculate this increase in required effective power.

$$
\% \Delta P_{E}=\frac{C_{T_{R}}-C_{T_{S}}}{C_{T_{S}}} \times 100=\frac{\Delta C_{F}}{C_{T_{S}}} \times 100
$$

where $C_{T_{R}}$ is total resistance coefficient in rough condition and $C_{T_{S}}$ is the total resistance coefficient in smooth condition.

Moreover, if the intention is to provide fixed effective power, the reduction in ship speed due to fouling condition was calculated. Then, the percentage reductions in speed at a fixed effective power were calculated by following the Eq. 7, 8 and 9.

$$
\begin{gathered}
C_{T_{R}}=C_{T_{S}}+\Delta C_{F} \\
V_{\text {reduced }}=\sqrt[3]{\frac{P_{E}}{0.5 \rho S C_{T_{R}}}} \\
\% \Delta V=\left(\frac{V-V_{\text {reduced }}}{V}\right) \times 100
\end{gathered}
$$

where $S$ is wetted surface area, $\rho$ is the density of water and $V$ is ship speed.

The $C_{T_{S}}$ values of the ships used in case studies were taken from the previously conducted experiments at the Kelvin Hydrodynamics Laboratory at the University of Strathclyde. 


\section{RESULTS}

\subsection{Frictional Resistance}

Having conducted towing tests using mixed barnacle configurations, it would be a deficiency not to compare mix type configuration with the $\mathrm{B}, \mathrm{M}$ and $\mathrm{S}$ type configurations presented in Demirel et al. [20]. This comparison aimed to investigate which type of barnacle in a tile has the dominant effect on frictional drag. For this reason, the experimental data for middle type and small type barnacle configurations for a Reynolds number of $\sim 4 \times 10^{6}$ were also taken from Demirel et al. [20] and compared to natural settlement mixed configuration.

Fig. 5. illustrates the percentage increases in $C_{F}$ at different Reynolds number for all coverage rates. It is important to note that within the mixed configurations, Reynolds number of which $\sim 4 \times 10^{6}$ is represented by the black circle (O) in the figure, was selected to be compared with the $\mathrm{B}, \mathrm{M}$ and $\mathrm{S}$ type barnacle configurations as it is the closest value to the selected Reynolds number for this comparison.

The results confirmed Schultz's hypothesis on selecting the largest roughness height in developing the scaling parameter for the surfaces covered with barnacles [15]. It is evident from Fig. 5., percentage increases in frictional resistance due to B type fouling configuration is close to the percentage increases due to standard mixed type barnacle configurations. The results indicate that the resistance profile of the mixed configuration is comparatively closer to B type barnacle's resistance profile. This means that the presence of B type barnacles overweighs the effect of comparatively small barnacles. Therefore, the B type configuration was selected to be used for a detailed assessment. 


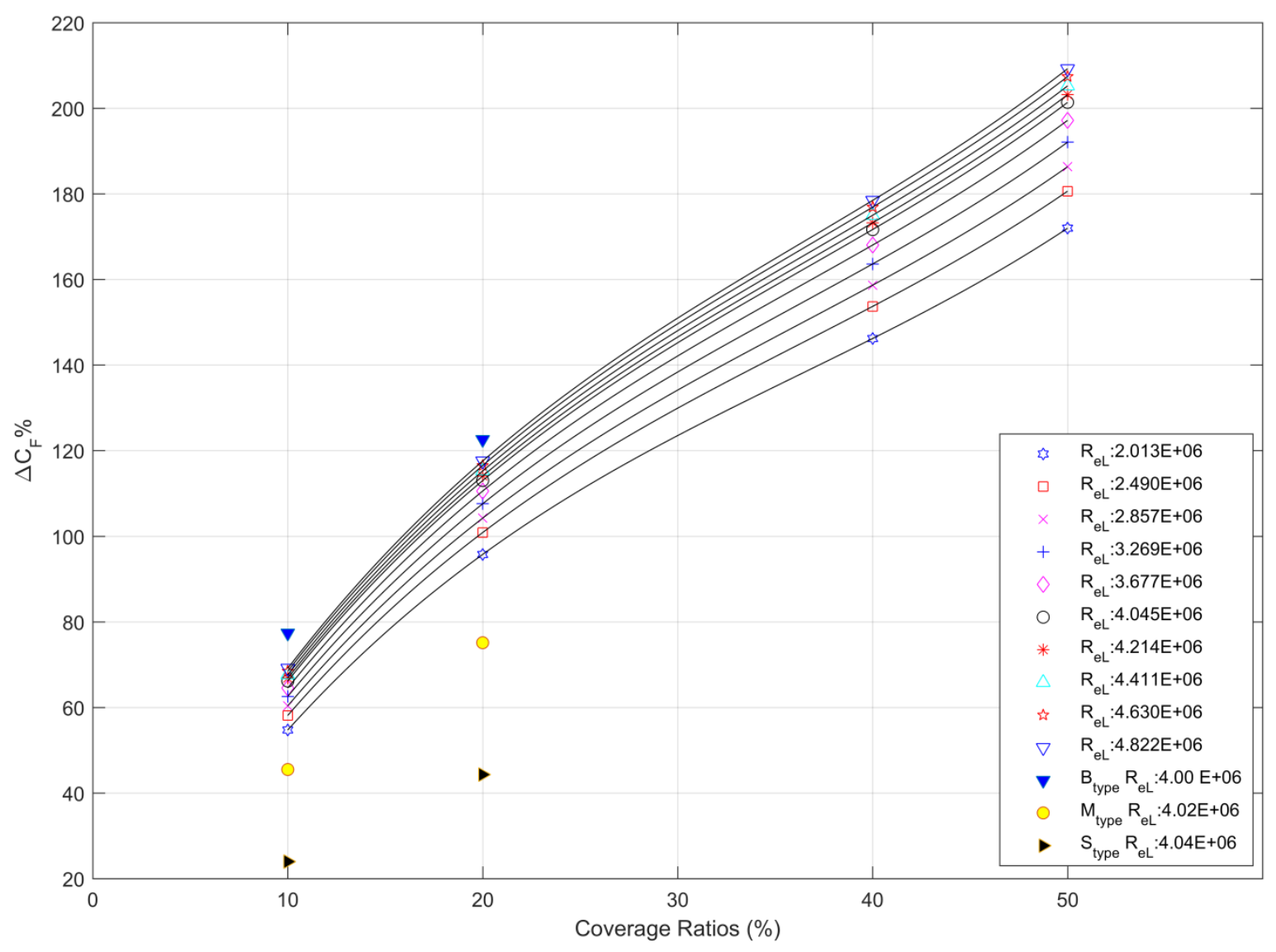

Fig. 5. Percentage increases in $\Delta \mathrm{C}_{\mathrm{F}}$ with respect to coverage ratios at different Reynolds number compared to the reference plate

Fig. 6. shows frictional resistance coefficients of test surfaces. It can be seen that the highest percentage increase with an average increase of $194 \%$ caused by NS mixed configuration with $50 \%$ coverage area, compared to the reference plate. The second-highest increase in frictional resistance coefficient is measured, as shown in Table 2, for the configuration of 50\% mixed ( 184\%) followed by $40 \%$ NS mixed $(\sim 165 \%), 40 \%$ mixed $(\sim$ $160 \%), 20 \% \mathrm{~B}(\sim 119 \%), 20 \%$ NS mixed $(\sim 109 \%), 20 \% \operatorname{mixed}(\sim 99 \%), 10 \% \mathrm{~B}(\sim 74 \%)$ ,10\% NS mixed $(\sim 63 \%)$, and $10 \%$ mixed $(\sim 52 \%)$.

It is evident from Fig. 6. that settlement pattern, coverage area, and size of barnacles in tiles have effects on the frictional resistance. As stated in the wall similarity' hypothesis, in the fully rough regime, $\mathrm{C}_{\mathrm{F}}$ is expected to be independent of Reynolds number and form drag on the roughness is the dominant phenomena that lead to momentum deficit. As illustrated in Fig. 6. the frictional resistance coefficients of test surfaces show dependency on Reynolds number. However, as shown in Fig. 6. this dependency is more dominant at low Reynolds number, whereas this dependency decreases with the increase in Reynolds number, especially above the Reynolds number of $4 \times 10^{6}$. This can be attributed the fact that after a certain threshold flow reaches to the fully rough regime. 


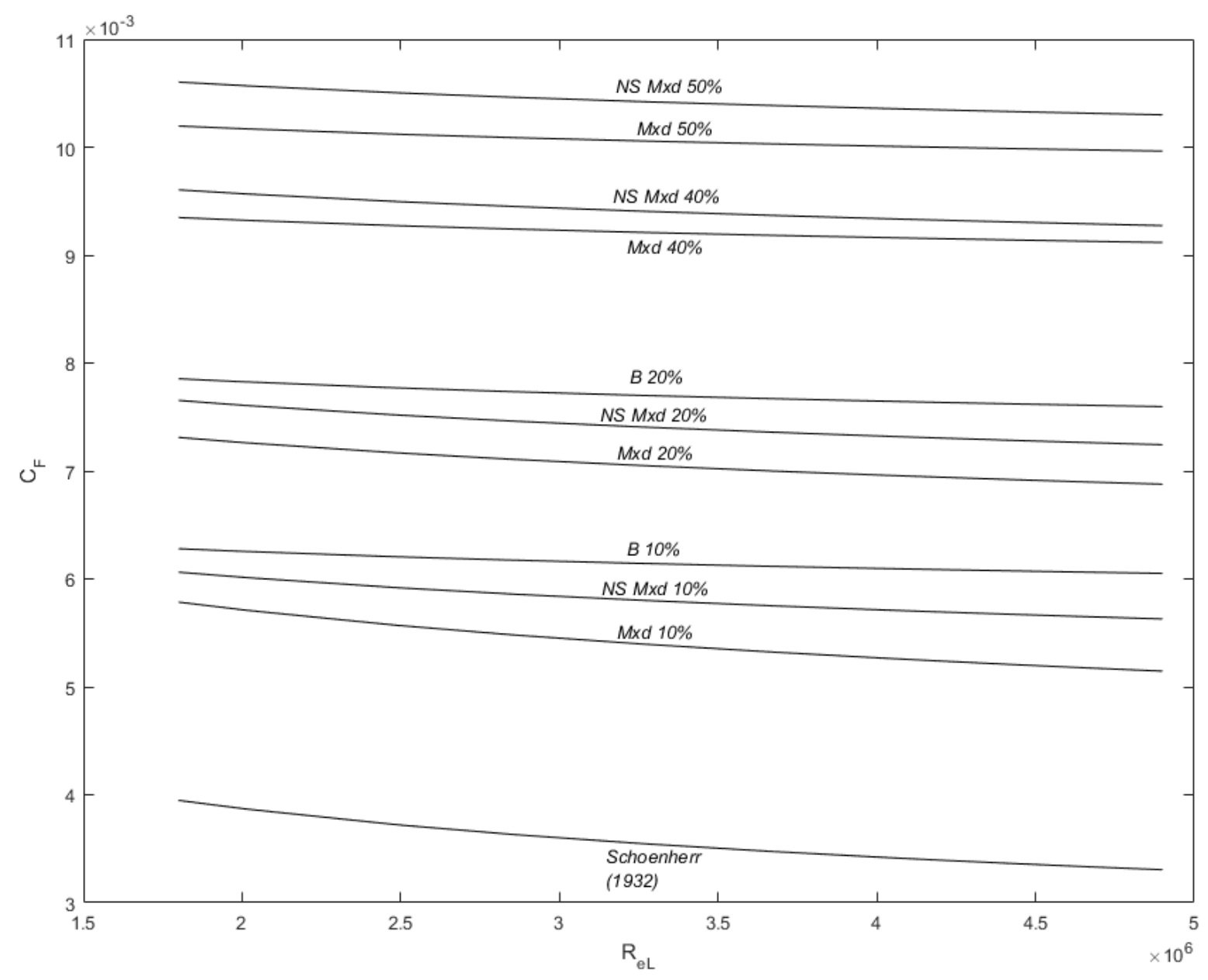

Fig. 6. Frictional resistance coefficients of test surfaces

The results presented in Fig. 6. and Table 2 indicate that as the percentage of coverage area increases, $\mathrm{C}_{\mathrm{F}}$ values increase. Average increases in $\mathrm{C}_{\mathrm{F}}$ for standard settlement mix type configurations were calculated as $52 \%$ for $10 \%$ coverage area (CA), $99 \%$ for $20 \%$ CA , $160 \%$ for $40 \% \mathrm{CA}$ and $184 \%$ for $50 \% \mathrm{CA}$, whereas, for NS mixed configurations, these values altered to $63 \%$ for $10 \% \mathrm{CA}, 109 \%$ for $20 \% \mathrm{CA}, 165 \%$ for $40 \% \mathrm{CA}$ and $194 \%$ for $50 \% \mathrm{CA}$.

Another assumption in Schultz [15] indicates that "the effect of increased per cent coverage of barnacle in drag is largest for small coverage and smaller for large coverage". It is important to note that the results presented in this paper confirm Schultz's assumption. For both settlement configurations, the rate of increase in $\mathrm{C}_{\mathrm{F}}$ between coverage areas of $10 \%$ and $20 \%$ are comparatively higher than that of $40 \%$ and $50 \%$ as shown in Fig. 6. and Table 2. These results confirm that until a certain level, increase in coverage area has a dominant effect on frictional resistance, however, once coverage area reaches this level the increase in coverage area has less impact on frictional resistance [20]. 
Table 2 Average changes in the $C_{F}$ values of the test plates with respect to the smooth plate

\begin{tabular}{cccc}
\hline Configuration & $\begin{array}{c}\text { Average change } \\
\text { in } \mathrm{C}_{\mathrm{F}}\end{array}$ & Configuration & $\begin{array}{c}\text { Average change } \\
\text { in } \mathrm{C}_{\mathrm{F}}\end{array}$ \\
\hline mxd $10 \%$ & $52 \%$ & NS mxd $10 \%$ & $63 \%$ \\
$\operatorname{mxd} 20 \%$ & $99 \%$ & NS mxd $20 \%$ & $109 \%$ \\
$\operatorname{mxd} 40 \%$ & $160 \%$ & NS mxd $40 \%$ & $165 \%$ \\
$\operatorname{mxd} 50 \%$ & $184 \%$ & NS mxd $50 \%$ & $194 \%$ \\
\hline
\end{tabular}

Table 3 Comparison of the $C_{F}$ values for the configurations with $10 \%$ and $20 \%$ coverage areas at different Reynolds number (Relative Difference, $\mathrm{D}(\%)$ is based on KarmanSchoenherr).

\begin{tabular}{|c|c|c|c|c|c|c|c|c|c|c|}
\hline \multirow{3}{*}{$\begin{array}{c}\text { Reynolds } \\
\text { Number }\end{array}$} & \multicolumn{10}{|l|}{$\mathrm{C}_{\mathrm{F}} \times 10^{-3}$} \\
\hline & \multirow{2}{*}{$\begin{array}{c}\begin{array}{c}\text { Karman- } \\
\text { Schoenherr }\end{array} \\
\text { Result }\end{array}$} & \multirow{2}{*}{$\frac{C_{R}}{\text { Result }}$} & \multicolumn{2}{|c|}{ Mxd 10\% } & \multicolumn{2}{|c|}{ NS mxd 10\% } & \multicolumn{2}{|c|}{$\operatorname{Mxd} 20 \%$} & \multicolumn{2}{|c|}{ NS mxd $20 \%$} \\
\hline & & & Result & $\mathrm{D}(\%)$ & Result & $\mathrm{D}(\%)$ & Result & $\mathrm{D}(\%)$ & Result & $\mathrm{D}(\%)$ \\
\hline $1.8 \times 10^{6}$ & 3.963 & N/A & 5.785 & 45.96 & 6.062 & 52.96 & 7.310 & 84.46 & 7.653 & 93.11 \\
\hline $2.01 \times 10^{6}$ & 3.886 & 0.4503 & 5.710 & 46.94 & 6.012 & 54.72 & 7.261 & 86.85 & 7.606 & 95.75 \\
\hline $2.49 \times 10^{6}$ & 3.743 & 0.4330 & 5.569 & 48.80 & 5.918 & 58.11 & 7.167 & 91.49 & 7.518 & 100.86 \\
\hline $2.86 \times 10^{6}$ & 3.653 & 0.3837 & 5.480 & 50.01 & 5.858 & 60.35 & 7.107 & 94.54 & 7.461 & 104.23 \\
\hline $3.27 \times 10^{6}$ & 3.568 & 0.3904 & 5.395 & 51.21 & 5.800 & 62.56 & 7.049 & 97.57 & 7.406 & 107.58 \\
\hline $3.68 \times 10^{6}$ & 3.495 & 0.4733 & 5.321 & 52.26 & 5.750 & 64.53 & 6.999 & 100.27 & 7.358 & 110.56 \\
\hline $4.05 \times 10^{6}$ & 3.437 & 0.3834 & 5.262 & 53.12 & 5.709 & 66.14 & 6.958 & 102.48 & 7.320 & 113.00 \\
\hline $4.22 \times 10^{6}$ & 3.412 & 0.3751 & 5.237 & 53.49 & 5.692 & 66.83 & 6.941 & 103.43 & 7.303 & 114.06 \\
\hline $4.41 \times 10^{6}$ & 3.385 & 0.3914 & 5.209 & 53.90 & 5.673 & 67.61 & 6.921 & 104.50 & 7.285 & 115.24 \\
\hline $4.63 \times 10^{6}$ & 3.356 & 0.4062 & 5.180 & 54.35 & 5.653 & 68.44 & 6.901 & 105.65 & 7.266 & 116.52 \\
\hline $4.82 \times 10^{6}$ & 3.332 & 0.4471 & 5.155 & 54.71 & 5.635 & 69.13 & 6.884 & 106.60 & 7.250 & 117.57 \\
\hline $4.90 \times 10^{6}$ & 3.323 & N/A & 5.145 & 54.85 & 5.629 & 69.41 & 6.877 & 106.97 & 7.243 & 117.99 \\
\hline
\end{tabular}

Table 4 Comparison of the $\mathrm{C}_{\mathrm{F}}$ values for the configurations with $40 \%$ and $50 \%$ coverage areas at different Reynolds number (Relative Difference, $\mathrm{D}(\%)$ is based on KarmanSchoenherr).

\begin{tabular}{|c|c|c|c|c|c|c|c|c|c|}
\hline \multirow{3}{*}{$\begin{array}{c}\text { Reynolds } \\
\text { Number }\end{array}$} & \multicolumn{9}{|l|}{$C_{F} \times 10^{-3}$} \\
\hline & $\begin{array}{c}\text { Karman- } \\
\text { Schoenherr }\end{array}$ & \multicolumn{2}{|c|}{ Mxd 40\% } & \multicolumn{2}{|c|}{ NS mxd 40\% } & \multicolumn{2}{|c|}{ Mxd 50\% } & \multicolumn{2}{|c|}{ NS Mxd 50} \\
\hline & Result & Result & $\mathrm{D}(\%)$ & Result & $\mathrm{D}(\%)$ & Result & $\mathrm{D}(\%)$ & Result & $\mathrm{D}(\%)$ \\
\hline $1.8 \times 10^{6}$ & 3.963 & 9.348 & 135.9 & 9.604 & 142.3 & 10.196 & 157.3 & 10.603 & 167.5 \\
\hline $2.01 \times 10^{6}$ & 3.886 & 9.322 & 139.9 & 9.567 & 146.2 & 10.169 & 161.7 & 10.568 & 172.0 \\
\hline $2.49 \times 10^{6}$ & 3.743 & 9.273 & 147.7 & 9.496 & 153.7 & 10.120 & 170.4 & 10.503 & 180.6 \\
\hline $2.86 \times 10^{6}$ & 3.653 & 9.241 & 152.9 & 9.450 & 158.7 & 10.088 & 176.1 & 10.461 & 186.3 \\
\hline $3.27 \times 10^{6}$ & 3.568 & 9.210 & 158.1 & 9.406 & 163.6 & 10.057 & 181.9 & 10.421 & 192.1 \\
\hline $3.68 \times 10^{6}$ & 3.495 & 9.183 & 162.8 & 9.367 & 168.0 & 10.030 & 187.0 & 10.385 & 197.2 \\
\hline $4.05 \times 10^{6}$ & 3.437 & 9.161 & 166.6 & 9.336 & 171.7 & 10.008 & 191.2 & 10.357 & 201.4 \\
\hline $4.22 \times 10^{6}$ & 3.412 & 9.151 & 168.2 & 9.322 & 173.2 & 9.998 & 193.0 & 10.344 & 203.2 \\
\hline $4.41 \times 10^{6}$ & 3.385 & 9.141 & 170.1 & 9.307 & 175.0 & 9.988 & 195.1 & 10.331 & 205.2 \\
\hline $4.63 \times 10^{6}$ & 3.356 & 9.130 & 172.1 & 9.292 & 176.9 & 9.977 & 197.3 & 10.316 & 207.4 \\
\hline $4.82 \times 10^{6}$ & 3.332 & 9.121 & 173.7 & 9.279 & 178.5 & 9.967 & 199.1 & 10.304 & 209.2 \\
\hline $4.90 \times 10^{6}$ & 3.323 & 9.117 & 174.4 & 9.273 & 179.1 & 9.964 & 199.9 & 10.299 & 210.0 \\
\hline
\end{tabular}


The effect of the settlement on the frictional resistance is jointly tabulated in Table 3 and Table 4 which shows the frictional resistance coefficients and relative differences $(D(\%))$ in $\mathrm{C}_{\mathrm{F}}$ values of the configurations and the smooth plate.

The results presented in Table 3 indicate that the $\mathrm{D}(\%)$ in $\mathrm{C}_{\mathrm{F}}$ were calculated in a range from $\sim 46 \%$ to $\sim 55 \%$ for $10 \%$ mixed and from $\sim 53 \%$ to $\sim 69.4 \%$ for $10 \%$ NS mixed configurations. These values altered to $\sim 84.5 \%$ at the lowest Reynolds number and to $\sim 107 \%$ at the highest Reynolds number for $20 \%$ mixed configurations. The relative differences for $20 \%$ NS mixed configuration were calculated to be from $\sim 93 \%$ to $\sim 118 \%$. The relative differences in the $\mathrm{C}_{\mathrm{F}}$ values for mixed $40 \%$ and NS mixed $40 \%$ configurations were predicted to be in a range from $\sim 136 \%$ to $\sim 174 \%$ and from $\sim 142 \%$ to $\sim 179 \%$, respectively. These ranges altered to from $\sim 157 \%$ to $\sim 200 \%$ for $50 \%$ mixed configuration and from $167.5 \%$ to $210 \%$ for $50 \%$ NS mixed configuration, as can be seen in Table 4.

An interesting point to note is that $\mathrm{D}(\%)$ in $\mathrm{C}_{\mathrm{F}}$ increases with the increasing Reynolds number for comparatively lower coverage rates $(10 \%$ and $20 \%$ coverage rates) due to settlement effect. The difference of $\mathrm{D}(\%)$ in $\mathrm{C}_{\mathrm{F}}$ for $10 \%$ mixed and $\mathrm{NS} 10 \%$ mixed was predicted to be $\sim 7 \%$ at the lowest Reynolds number and $\sim 14.6 \%$ at the highest Reynolds number whereas these values altered to $\sim 8.65 \%$ and $\sim 11 \%$ for $20 \%$ mixed and NS $20 \%$ mixed at the lowest and the highest Reynolds number, respectively. Contrarily, the $\mathrm{D}(\%)$ in $\mathrm{C}_{\mathrm{F}}$ decreases with increasing Reynolds number for higher coverage rates $(40 \%$ and $50 \%$ coverage rates). As demonstrated in Table 4, the change between $\mathrm{D}(\%)$ in $\mathrm{C}_{\mathrm{F}}$ for $40 \%$ mixed and NS $40 \%$ mixed was calculated to be $\sim 6.5 \%$ and $\sim 4.7 \%$ whereas these values altered to $\sim 10.3 \%$ and $\sim 10.1 \%$ at lowest and highest Reynolds number respectively. These results also confirm that the effect of settlement disappears with increasing Reynolds number after a certain coverage rate.

It is interesting to note that the average change in $\mathrm{C}_{\mathrm{F}}$ between $40 \%$ mixed settlement and $40 \% \mathrm{NS}$ mixed is slightly lower than the value expected, so the authors believe that there is a certain room for further investigations.

\subsection{Roughness Functions}

The roughness functions of test surfaces along with the Colebrook type roughness function of Grigson [31], the analytical fit of Ioselevich and Pilipenko [30] developed by using the roughness function data of Nikuradse [32] and the analytical fit of Demirel et al. [33] based on the roughness function data of Schultz and Flack [34] were illustrated in Fig. 7.

The roughness length scale $k$ for the surfaces covered with barnacles was calculated through $k=0.059 h$ (\%coverage) ${ }^{0.5}$, as suggested in Schultz [15]. It is important to note that $h$ was taken as the highest roughness height, which is $5 \mathrm{~mm}$ in this study based on the assumption that largest roughness height has a dominant influence on frictional resistance [15].

Fig. 7. shows that roughness functions of the surfaces follow an upward trend with the increasing roughness Reynolds number as expected. It is evident that no collapse was observed between the test results and Colebrook-type roughness functions of Grigson [31] by using the same roughness length scale formula given by Schultz [15]. Fig. 7. shows that the flow over the majority of the test surfaces is fully rough, and the roughness functions showed 
a logarithmic dependence on $k^{+}$which confirms that the roughness functions of presented test surfaces agree well with the roughness functions of Grigson [31].

Since the only parameter that changes in roughness length scale formula is the coverage rate, the roughness function values of test surfaces which have the same coverage rates, are positioned on the same range on the logarithmic $k^{+}$axis. As expected, NS mixed $50 \%$ and mixed $50 \%$ showed the highest roughness function values and these followed by the test surfaces of NS mixed $40 \%$, mixed $40 \%$, B $20 \%$, NS mixed $20 \%$, mixed $20 \%$, B $10 \%$, NS mixed $10 \%$ and $\mathrm{B} 10 \%$.

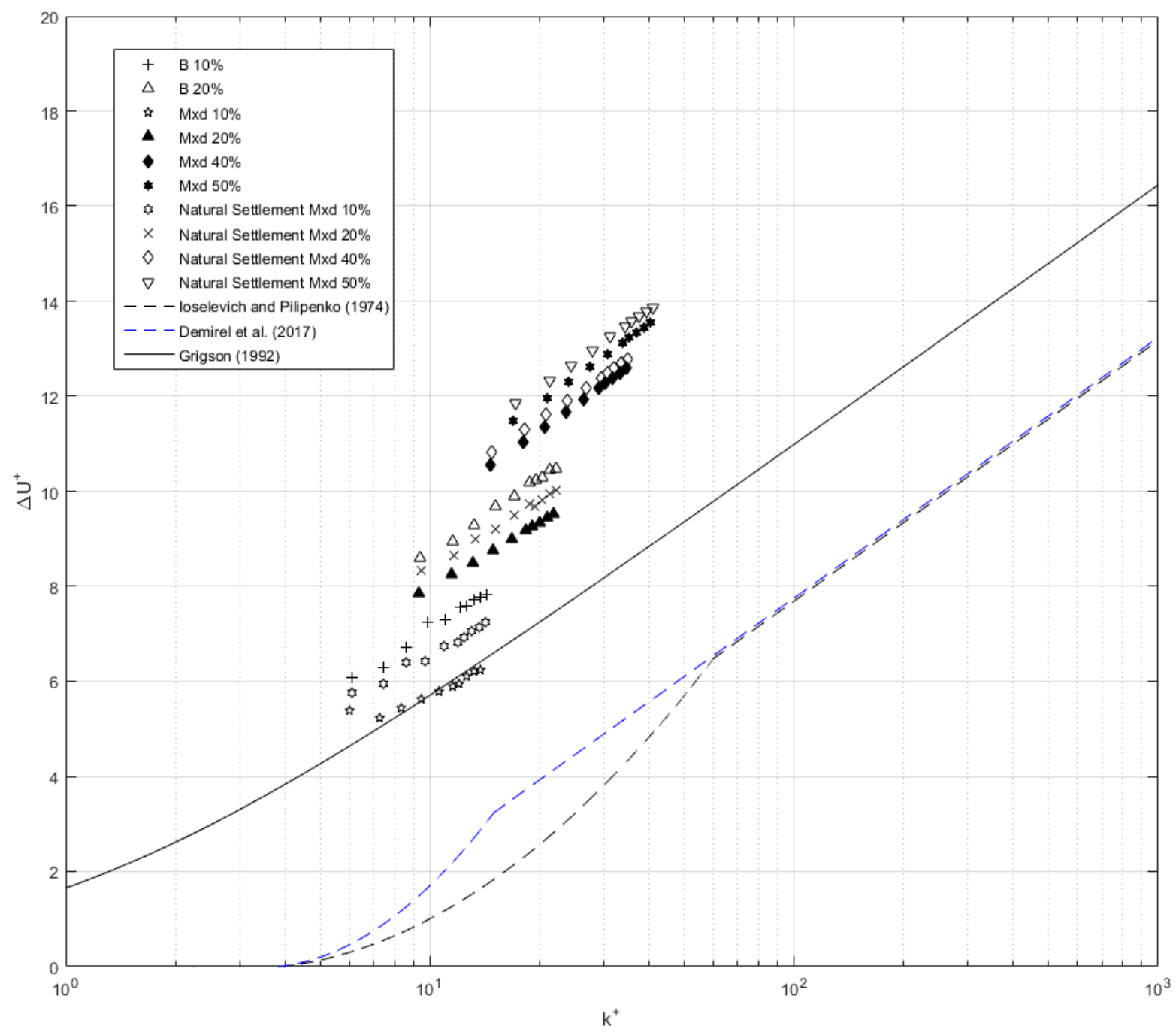

Fig. 7. Roughness functions for test surfaces $k=0.059 h$ (\%coverage) ${ }^{0.5}$ together with roughness function models 


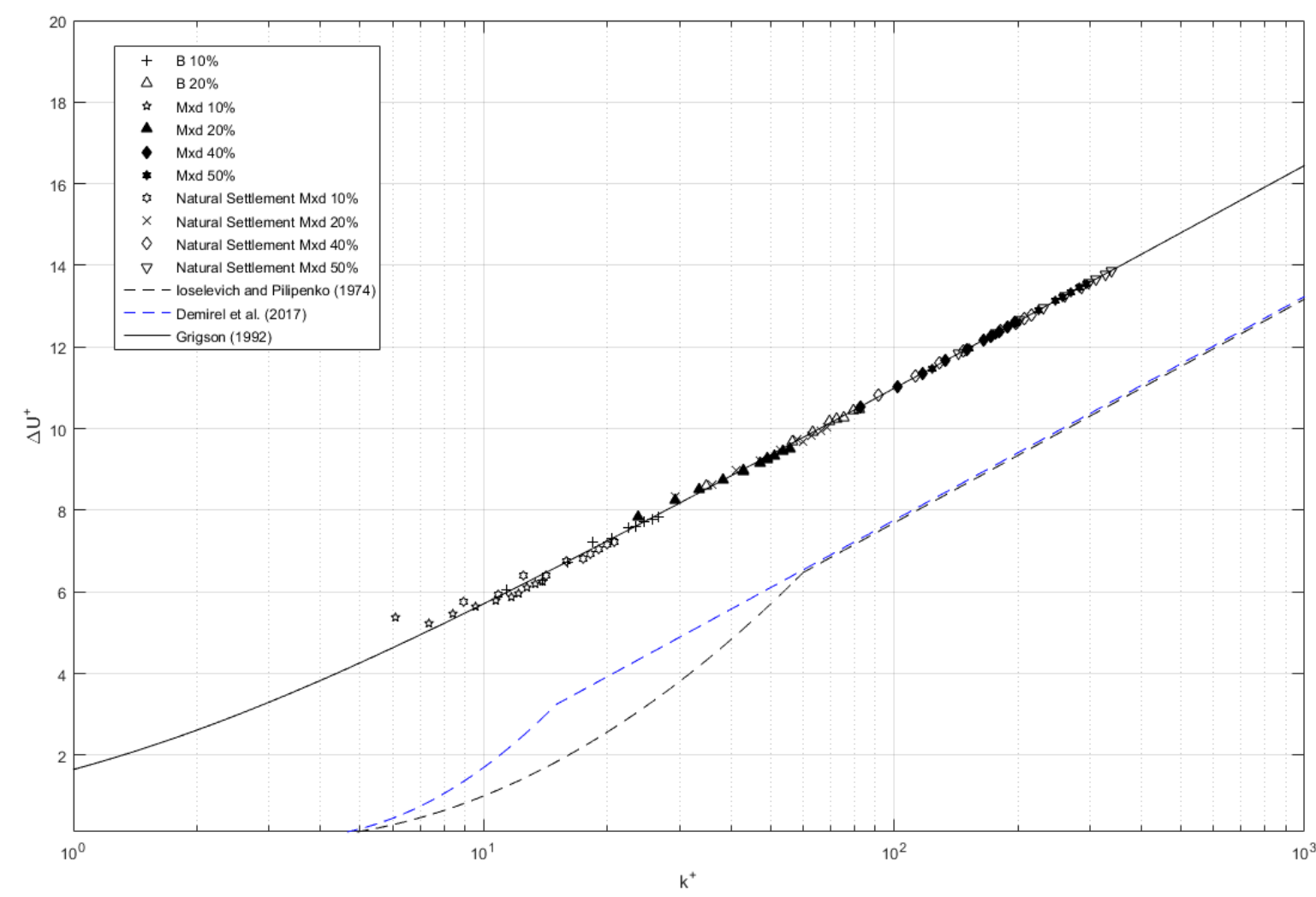

Fig. 8. Roughness functions for all the test surfaces, using corresponding $k_{G}$ values together with roughness function models.

Although no collapse was observed between test surfaces and given roughness function model by using roughness length scale of Schultz [15], this can be achieved by using different scaling for each test surface as suggested by Demirel et al. [20].

Therefore, roughness function values $\left(\Delta U^{+}\right)$were employed in the roughness function formula of Grigson and corresponding roughness Reynolds numbers $\left(k^{+}\right)$were calculated as explained in Demirel et al. [20] through Eq.10. Following this, roughness lengths named as $k_{G}$ by Demirel et al. [20] were calculated in order to have excellent agreement with a roughness function of Grigson [31].

$$
\Delta U^{+}=\left(\frac{1}{\kappa}\right) \ln \left(1+k^{+}\right)
$$

The results presented in Fig. 8. show that excellent agreement was obtained between test surfaces and Colebrook-type roughness function as so-called hydrodynamic roughness length scales, $k_{G}$ values are used as roughness lengths. These results confirm that the roughness functions of surfaces still require to be obtained experimentally. The developed roughness length scales or analytic fits are not applicable for every kind of surfaces

\subsection{Uncertainty Estimates}

By following the ITTC [35] procedure, uncertainty estimations were made for the drag coefficients and roughness functions by means of repeatability tests. These tests were 
conducted at two speeds representing slow speed and high speed, which are $1.857 \mathrm{~ms}^{-1}$ and $3.591 \mathrm{~ms}^{-1}$. The corresponding Reynolds numbers of these speeds are $2.6 \times 10^{6}$ and $5 \times 10^{6}$, respectively.

For the B-type barnacle configuration, the bias uncertainty in $\mathrm{C}_{\mathrm{F}}$ ranged from $\pm 1.9 \%$ at the lowest Reynolds number to $\pm 0.7 \%$ at the highest Reynolds number, while the precision uncertainty in $\mathrm{C}_{\mathrm{F}}$ ranged from $\pm 0.6 \%$ at the lower Reynolds number to $\pm 0.2 \%$ at the higher Reynolds number. The overall uncertainty in $\mathrm{C}_{\mathrm{F}}$ ranged from $\pm 2 \%$ at the lower Reynolds number to $\pm 0.7 \%$ at the higher Reynolds number. The total uncertainty in $\Delta U^{+}$ranged from $\pm 5.3 \%$ at the lowest Reynolds number to $\pm 0.8 \%$ at the highest Reynolds number for this type of configuration.

For the standard settlement mixed configuration, the resulting bias and precision uncertainty for $\mathrm{C}_{\mathrm{F}}$ may vary from $\pm 7.07 \%$ at the lowest Reynolds number to $\pm 2.02 \%$ at the highest Reynolds number. In $\Delta U^{+}$uncertainty, the values remained between $\pm 12 \%$ and $\pm 2.94 \%$ respectively in lower and higher Reynolds number.

For the NS mixed configuration, the resulting bias and precision uncertainty in $\mathrm{C}_{\mathrm{F}}$ ranged from $\pm 7.07 \%$ at the lowest Reynolds number to $\pm 1.95 \%$ at the highest Reynolds number while in $\Delta U^{+}$uncertainty values remained between $\pm 11.4 \%$ and $\pm 2.67 \%$ respectively in lower and higher Reynolds number.

The overall uncertainty levels of the drag coefficients are satisfactory in comparison to other experiments given in the literature such as Demirel et al. [20] and Schultz [15]. These very small precision limits reveal the acceptable repeatability of the experiments.

\subsection{Prediction of the change in Frictional resistance, Effective power and Speed reductions at ship scale}

The changes in frictional resistance coefficient $\Delta \mathrm{C}_{\mathrm{F}}$ for ship scale were calculated by using the similarity law scaling procedure [17]. The calculated roughness functions and roughness Reynolds numbers for the test surfaces were employed in a prediction code which applies the similarity law scaling procedure, and then $\Delta \mathrm{C}_{\mathrm{F}}$ values were calculated.

The full-scale predictions in this study were made for flat plates representing the length of $230 \mathrm{~m}$ container ship, length of $270 \mathrm{~m} \mathrm{LNG} \mathrm{ship,} \mathrm{length} \mathrm{of} 180 \mathrm{~m}$ bulk carrier, length of 120 $\mathrm{m}$ special purpose vessel, length of $60 \mathrm{~m}$ special purpose vessel and length of $250 \mathrm{~m}$ tanker ship. Then, calculated $\Delta \mathrm{C}_{\mathrm{F}}$ values were plotted for an appropriate range of ship speed for the case studies, similar to those presented by Demirel et al. [36]. Fig. 9. illustrates the added frictional resistance diagram for a $250 \mathrm{~m}$ tanker ship with different fouling conditions. The corresponding added frictional resistance diagrams for other ships used as case studies can be found in Fig. A1-A6 in the appendices. 


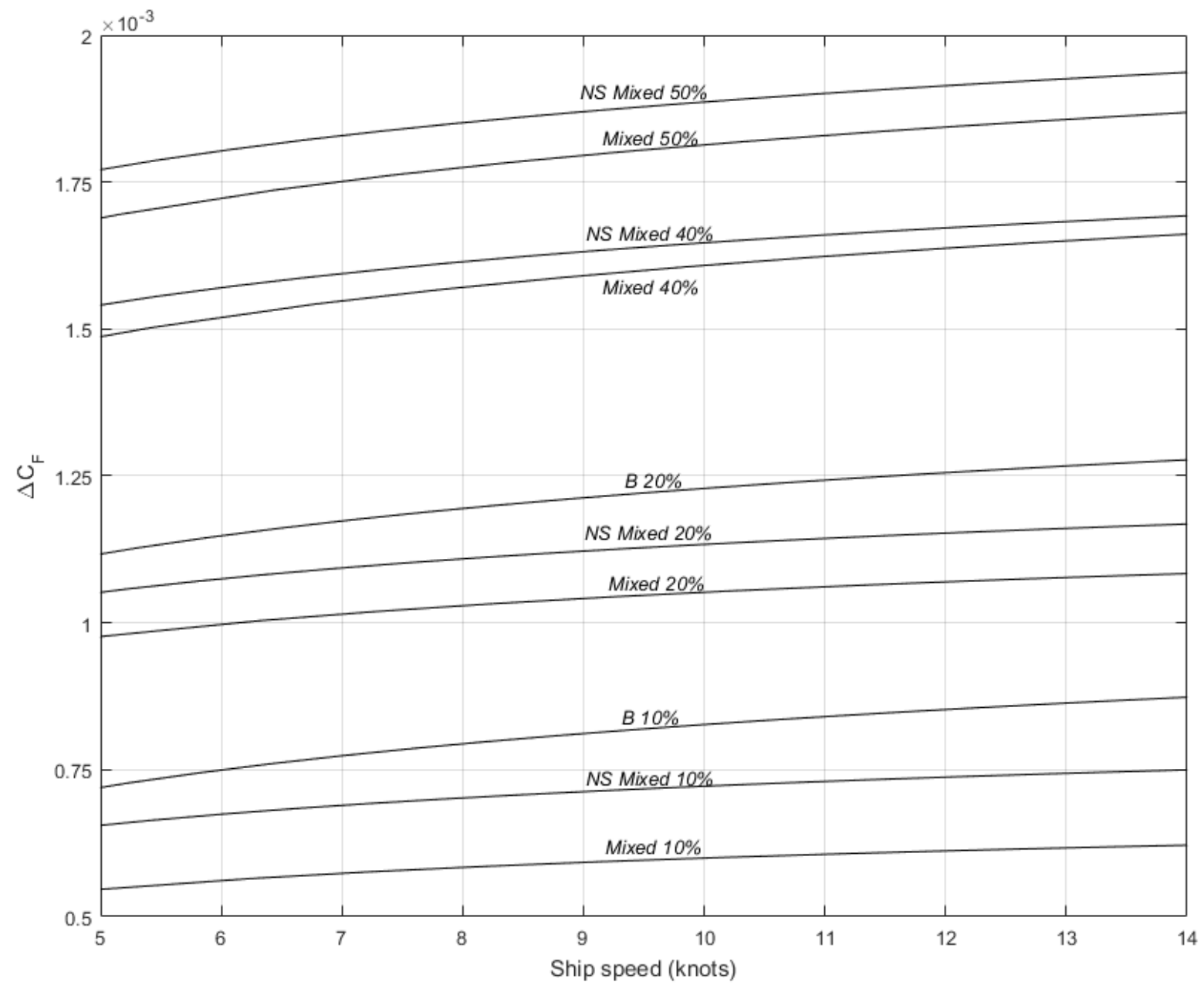

Fig. 9. Added frictional resistance diagram for a $250 \mathrm{~m}$ tanker ship with different barnacle fouling conditions

The frictional resistances in fouled conditions were compared with the calculated $\mathrm{C}_{\mathrm{F}}$ values through Karman-Schoenherr [28], which represents the smooth conditions. Then, all percentage increases in $\Delta \mathrm{C}_{\mathrm{F}}$ and hence $\Delta \mathrm{P}_{\mathrm{E}}$ for the case ships at cruise speed were summarized in Table 5.

The percentage increases for $270 \mathrm{~m}$ LNG ship sailing at 12 knots were given in Table 5. Increases in $\Delta \mathrm{C}_{\mathrm{F}}$ vary in a range from $42.43 \%$ to $58.91 \%$ and change in $\Delta \mathrm{P}_{\mathrm{E}}$ vary from $26.69 \%$ to $37.11 \%$ for the configurations of the $10 \%$ coverage rate. While $20 \%$ coverage rate caused an increase in these values from $74.2 \%$ to 87.59 for $\Delta \mathrm{C}_{\mathrm{F}}$ and from $46.65 \%$ to 54.91 for $\Delta \mathrm{P}_{\mathrm{E}}$, the configurations of $40 \%$ coverage increased these values to $\sim 116 \%$ and $\sim 72 \%$ for $\Delta \mathrm{C}_{\mathrm{F}}$ and $\Delta \mathrm{P}_{\mathrm{E}}$ respectively. Finally, the predictions for $50 \%$ mixed are $128.06 \%$ for $\triangle \mathrm{CF}$ and $80.04 \% \Delta \mathrm{PE}$, whereas these values are $133.77 \%$ for $\Delta \mathrm{CF}$ and $83.65 \%$ for $\Delta \mathrm{PE}$ for $50 \% \mathrm{NS}$ mixed for the percentage increases in $\Delta \mathrm{C}_{\mathrm{F}}$ and $\Delta \mathrm{P}_{\mathrm{E}}$, respectively.

The full-scale predictions for the $180 \mathrm{~m}$ bulk-carrier at 12 knots were made as to be in a range from $44.15 \%$ to 61.20 for $\Delta \mathrm{C}_{\mathrm{F}}$ and from $30.68 \%$ to $42.72 \%$ for $\Delta \mathrm{P}_{\mathrm{E}}$ for the configurations of $10 \%$ coverage. These numbers altered to the values from $77.47 \%$ to $90.89 \%$ in $\Delta \mathrm{C}_{\mathrm{F}}$ and from $53.81 \%$ to $63.26 \%$ in $\Delta \mathrm{P}_{\mathrm{E}}$ for $20 \%$ coverage rate, respectively. The $40 \%$ and 
$50 \%$ configurations caused increases between $117.98 \%$ and $139.34 \%$ in $\Delta \mathrm{C}_{\mathrm{F}}$ and between $82.43 \%$ and $96.87 \%$ in $\Delta \mathrm{P}_{\mathrm{E}}$ respectively.

On the other hand, the $60 \mathrm{~m}$ special purpose vessel sailing at $12 \mathrm{knots}$, under the fouled conditions that tested in the study, showed average increases of $58.83 \%$ and $94.14 \%$ in $\Delta \mathrm{C}_{\mathrm{F}}$ $23.33 \%$ and $37.33 \%$ in $\Delta \mathrm{P}_{\mathrm{E}}$ for $10 \%$ and $20 \%$ configurations respectively. The configurations of $40 \%$ mixed and $40 \%$ NS mixed lead to $134.96 \%$ and $137.72 \%$ increases in $\Delta \mathrm{C}_{\mathrm{F}}$ and $53.6 \%$ and $54.7 \%$ increases in $\Delta \mathrm{P}_{\mathrm{E}}$, whereas these values altered to $152.78 \%$ and $153.84 \%$ in $\Delta \mathrm{C}_{\mathrm{F}}$ and $60.71 \%$ and $60.92 \%$ in $\Delta \mathrm{P}_{\mathrm{E}}$ respectively for $50 \%$ mixed and $50 \% \mathrm{NS}$ mixed configurations.

The results for $120 \mathrm{~m}$ special purpose vessel sailing at 14 knots showed $46.96 \%, 56.98 \%$ and $66.67 \%$ increase in $\Delta \mathrm{C}_{\mathrm{F}}$, whereas increases in $\Delta \mathrm{P}_{\mathrm{E}}$ were predicted as $29.44 \%, 35.68 \%$ and $41.76 \%$ for $10 \%$ configurations of mixed, NS mixed and B type respectively. The $20 \%$ coverage rate in the same sequence showed $82.57 \%, 89.27 \%$ and $98.15 \%$ increases in $\Delta \mathrm{C}_{\mathrm{F}}$ and $51.77 \%, 55.94 \%$ and $61.45 \%$ increases in $\Delta \mathrm{P}_{\mathrm{E}}$. The increases for the configurations of $40 \%$ of mixed, NS mixed, and $50 \%$ of mixed, NS mixed were predicted as $128.26 \%$, $130.39 \%, 144.47 \%$ and $149.71 \%$ in $\Delta \mathrm{C}_{\mathrm{F}}$ and $80.34 \%, 81.77 \%, 90.57 \%$ and 93.9 in $\Delta \mathrm{P}_{\mathrm{E}}$ respectively.

The predictions for $250 \mathrm{~m}$ tanker ship sailing at 14 knots showed a possible increase of $44.07 \%, 53.35 \%$ and $62.13 \%$ in $\Delta \mathrm{C}_{\mathrm{F}}$ whilst $\Delta \mathrm{P}_{\mathrm{E}}$ exposed to increases of $24.51 \%, 29.61 \%$ and $34.49 \%$ for $10 \%$ configurations of mixed, NS mixed and $\mathrm{B}$ type respectively. The configurations of $20 \%$ coverage caused an average increase of $83.7 \%$ and $46.46 \%$ in $\Delta \mathrm{C}_{\mathrm{F}}$ and $\Delta \mathrm{P}_{\mathrm{E}}$, respectively. The $40 \%$ and $50 \%$ configurations increased $\mathrm{C}_{\mathrm{F}}$ and $\mathrm{P}_{\mathrm{E}}$ in a range from $118.24 \%$ to $137.68 \%$ and from $65.61 \%$ to $76.44 \%$, respectively.

Finally, the percentage increases in $\Delta \mathrm{C}_{\mathrm{F}}$ and $\Delta \mathrm{P}_{\mathrm{E}}$ for $230 \mathrm{~m}$ container ship which sails at 24 knots are predicted to be $49.66 \%$ and $31.92 \%$ for $10 \%$ mixed $60.05 \%$ and $38.62 \%$ for $10 \%$ NS mixed and $71.82 \%$ and $46.15 \%$ for $10 \%$ B type configuration, respectively. These values have changed to $86.08 \%$ and $55.3 \%$ for $20 \%$ mixed $93.3 \%$ and $59.78 \%$ for $20 \%$ NS mixed and $103.16 \%$ and 66.22 for $20 \%$ B type configuration. As expected, the highest values were observed for the $50 \%$ mixed and $50 \%$ NS mixed configurations with increases of $149.01 \%$ and $153.67 \%$ in $\Delta \mathrm{C}_{\mathrm{F}}$ and $95.74 \%$ and $98.74 \%$ in $\Delta \mathrm{P}_{\mathrm{E}}$ respectively. The configurations of $40 \%$ mixed and $40 \% \mathrm{NS}$ mixed showed close increases to the $50 \%$ configurations with the increases of $133.32 \%$ and $134.24 \%$ in $\Delta \mathrm{C}_{\mathrm{F}}$ and $85.51 \%$ and $86.33 \%$ in $\Delta \mathrm{P}_{\mathrm{E}}$, respectively.

Overall, the percentage differences in $\mathrm{P}_{\mathrm{E}}$ between the configurations that settled according to the ASTM standards and according to the proposed natural settlement showed interestingly close values to each other. The highest difference in $\mathrm{P}_{\mathrm{E}}$ with $6.7 \%$ belonged to the $10 \%$ coverage configurations of container ship case whereas this value was $10.39 \%$ for the $\mathrm{C}_{\mathrm{F}}$. The results showed that the differences in $\mathrm{C}_{\mathrm{F}}$ and $\mathrm{P}_{\mathrm{E}}$ between natural settlement and standard settlement configurations for those which have the same coverage rate decreased as the coverage rate increased from $10 \%$ to $50 \%$. Interestingly, configurations of $40 \%$ coverage showed almost identical increases so that the lowest differences between $\mathrm{C}_{\mathrm{F}}$ and $\mathrm{P}_{\mathrm{E}}$ were observed between $40 \%$ NS mixed and 40\% mixed configurations. These values are slightly lower than the values that authors estimated, and there is a room for researching the reason for this difference. The differences between $\mathrm{C}_{\mathrm{F}}$ and $\mathrm{P}_{\mathrm{E}}$ can be seen in Table 5 . 
The percentage speed reductions at fixed effective power in cruise speeds due to fouling conditions were calculated through Eq. 6 and shown in Table 6. The results showed that the percentage reduction in speed ranges between 8.82 and $20.46 \%$, which corresponds to a speed loss of 2.12 - 4.91 knots for $230 \mathrm{~m}$ container ship sailing at 24 knots. The percentage speed reduction for $270 \mathrm{~m} \mathrm{LNG} \mathrm{ship} \mathrm{sailing} \mathrm{at} 12$ knots was predicted to be in a range between $7.58 \%$ and $18.34 \%$ which converts to a speed loss of $0.91-2.32$ knots.

The predictions for $180 \mathrm{~m}$ bulk-carrier and $60 \mathrm{~m}$ special purpose vessel sailing at $12 \mathrm{knots}$ were carried out, and results showed that the percentage reduction in ship speed changes between $8.53 \%$ and $20.21 \%$ and between $5.71 \%$ and $14.66 \%$ which correspond to speed losses of 1.05-2.48 knots and 0.68-1.78 knots respectively.

The fouling conditions in the study reduced the ship speed in a range between $8.24 \%$ and $19.81 \%$ and between $7.05 \%$ and $17.24 \%$ respectively for the ships of $120 \mathrm{~m}$ special purpose vessel and $250 \mathrm{~m}$ tanker ship sailing at 14 knots. The speed losses for these ships ranged between 1.14 and 2.72 knots, and between 0.98 and 2.42 knots respectively for $120 \mathrm{~m}$ special purpose vessel and $250 \mathrm{~m}$ tanker ship. 
Table 5 Increases in frictional resistance and powering compared to smooth conditions

\begin{tabular}{|c|c|c|c|c|c|c|c|c|c|c|c|c|}
\hline Ship Type & \multicolumn{2}{|c|}{$\begin{array}{c}230 \mathrm{~m} \\
\text { Container ship } \\
\text { @ } 24 \text { knots }\end{array}$} & \multicolumn{2}{|c|}{$\begin{array}{c}270 \mathrm{~m} \\
\text { LNG ship } \\
\text { @ } 12 \text { knots }\end{array}$} & \multicolumn{2}{|c|}{$\begin{array}{c}180 \mathrm{~m} \\
\text { Bulk-carrier } \\
@ 12 \text { knots } \\
\end{array}$} & \multicolumn{2}{|c|}{$\begin{array}{c}120 \mathrm{~m} \text { Special } \\
\text { purpose vessel } \\
\text { @ } 14 \text { knots }\end{array}$} & \multicolumn{2}{|c|}{$\begin{array}{l}60 \mathrm{~m} \text { Special } \\
\text { purpose vessel } \\
\text { (a) } 12 \text { knots }\end{array}$} & \multicolumn{2}{|c|}{$\begin{array}{c}250 \mathrm{~m} \\
\text { Tanker ship } \\
@ 14 \text { knots } \\
\end{array}$} \\
\hline$\%$ Change & $\% \Delta \mathrm{C}_{\mathrm{l}}$ & ${ }_{0} \Delta \mathrm{P}_{\mathrm{E}}$ & $\% \Delta \mathrm{C}_{\mathrm{I}}$ & ${ }_{0} \Delta \mathrm{P}_{\mathrm{E}}$ & $\% \Delta C_{\mathrm{F}}$ & ${ }_{0} \Delta \mathrm{P}_{\mathrm{E}}$ & $\% \Delta \mathrm{C}_{\mathrm{F}}$ & ${ }_{0} \Delta \mathrm{P}_{\mathrm{E}}$ & $\% \Delta \mathrm{C}_{\mathrm{F}}$ & ${ }_{0} \Delta \mathrm{P}_{\mathrm{E}}$ & $\% \Delta \mathrm{C}_{\mathrm{F}}$ & ${ }_{0} \Delta \mathrm{P}_{\mathrm{E}}$ \\
\hline $10 \%$ Mixed & 49.66 & 31.92 & 42.43 & 26.69 & 44.15 & 30.68 & 46.96 & 29.44 & 48.53 & 19.27 & 44.07 & 24.51 \\
\hline $10 \%$ NS Mixed & 60.05 & 38.62 & 51.36 & 32.24 & 52.95 & 36.92 & 56.98 & 35.68 & 59.06 & 23.40 & 53.35 & 29.61 \\
\hline $10 \% \mathrm{~B}$ & 71.82 & 46.15 & 58.91 & 37.11 & 61.20 & 42.72 & 66.67 & 41.76 & 68.90 & 27.32 & 62.13 & 34.49 \\
\hline $20 \%$ Mixed & 86.08 & 55.33 & 74.20 & 46.65 & 77.47 & 53.81 & 82.57 & 51.77 & 86.19 & 34.23 & 76.91 & 42.75 \\
\hline $20 \%$ NS Mixed & 93.27 & 59.78 & 79.48 & 50.14 & 83.76 & 58.10 & 89.27 & 55.94 & 93.47 & 37.06 & 83.09 & 46.12 \\
\hline $20 \% \mathrm{~B}$ & 103.16 & 66.22 & 87.59 & 54.91 & 90.89 & 63.26 & 98.15 & 61.45 & 102.77 & 40.71 & 91.09 & 50.50 \\
\hline $40 \%$ Mixed & 133.32 & 85.51 & 115.02 & 71.79 & 117.98 & 82.43 & 128.26 & 80.34 & 134.96 & 53.60 & 118.24 & 65.61 \\
\hline $40 \%$ NS Mixed & 134.24 & 86.33 & 116.71 & 73.07 & 121.31 & 84.41 & 130.39 & 81.77 & 137.72 & 54.70 & 120.33 & 66.81 \\
\hline 50\% Mixed & 149.01 & 95.74 & 128.06 & 80.40 & 133.17 & 93.02 & 144.47 & 90.57 & 152.78 & 60.71 & 132.88 & 73.76 \\
\hline $50 \%$ NS Mixed & 153.67 & 98.74 & 133.77 & 83.65 & 139.34 & 96.87 & 149.71 & 93.90 & 153.84 & 60.92 & 137.68 & 76.44 \\
\hline
\end{tabular}

Table 6 Speed reductions in fouled conditions for ships compared to smooth conditions

\begin{tabular}{|c|c|c|c|c|c|c|c|c|c|c|c|c|c|c|c|c|c|c|}
\hline \multirow{2}{*}{$\begin{array}{c}\text { Ship Type } \\
\text { Configurations }\end{array}$} & \multicolumn{3}{|c|}{$\begin{array}{c}230 \mathrm{~m} \\
\text { Container ship } \\
\text { @ } 24 \text { knots }\end{array}$} & \multicolumn{3}{|c|}{$\begin{array}{c}270 \mathrm{~m} \\
\text { LNG ship } \\
\text { @ } 12 \text { knots }\end{array}$} & \multicolumn{3}{|c|}{$\begin{array}{c}180 \mathrm{~m} \\
\text { Bulk-carrier } \\
\text { @ } 12 \text { knots }\end{array}$} & \multicolumn{3}{|c|}{$\begin{array}{c}120 \mathrm{~m} \\
\text { Special purpose vessel } \\
\text { @ } 14 \text { knots }\end{array}$} & \multicolumn{3}{|c|}{$\begin{array}{c}60 \mathrm{~m} \\
\text { Special purpose vessel } \\
\text { @12 knots }\end{array}$} & \multicolumn{3}{|c|}{$\begin{array}{c}250 \mathrm{~m} \\
\text { Tanker ship } \\
\text { @ } 14 \text { knots }\end{array}$} \\
\hline & $\begin{array}{l}\text { Ship } \\
\text { Speed in } \\
\text { smooth } \\
\text { condition }\end{array}$ & $\begin{array}{l}\text { Reduced } \\
\text { Speed for } \\
\text { fixed } \\
\text { EHP }\end{array}$ & $\begin{array}{c}\quad \% \\
\text { reduction } \\
\text { in speed } \\
\text { for fixed } \\
\text { EHP } \\
\end{array}$ & $\begin{array}{l}\text { Ship } \\
\text { Speed in } \\
\text { smooth } \\
\text { condition }\end{array}$ & $\begin{array}{l}\text { Reduced } \\
\text { Speed for } \\
\text { fixed } \\
\text { EHP }\end{array}$ & $\begin{array}{c}\quad \% \\
\text { reduction } \\
\text { in speed } \\
\text { for fixed } \\
\text { EHP } \\
\end{array}$ & $\begin{array}{l}\text { Ship } \\
\text { Speed in } \\
\text { smooth } \\
\text { condition }\end{array}$ & $\begin{array}{l}\text { Reduced } \\
\text { Speed for } \\
\text { fixed } \\
\text { EHP }\end{array}$ & $\begin{array}{c}\quad \% \\
\text { reduction } \\
\text { in speed } \\
\text { for fixed } \\
\text { EHP } \\
\end{array}$ & $\begin{array}{l}\text { Ship } \\
\text { Speed in } \\
\text { smooth } \\
\text { condition }\end{array}$ & $\begin{array}{l}\text { Reduced } \\
\text { Speed for } \\
\text { fixed } \\
\text { EHP }\end{array}$ & $\begin{array}{c}\quad \% \\
\text { reduction } \\
\text { in speed } \\
\text { for fixed } \\
\text { EHP } \\
\end{array}$ & $\begin{array}{l}\text { Ship } \\
\text { Speed in } \\
\text { smooth } \\
\text { condition }\end{array}$ & $\begin{array}{l}\text { Reduced } \\
\text { Speed for } \\
\text { fixed } \\
\text { EHP }\end{array}$ & $\begin{array}{c}\quad \% \\
\text { reduction } \\
\text { in speed } \\
\text { for fixed } \\
\text { EHP } \\
\end{array}$ & $\begin{array}{l}\text { Ship } \\
\text { Speed in } \\
\text { smooth } \\
\text { condition }\end{array}$ & $\begin{array}{l}\text { Reduced } \\
\text { Speed for } \\
\text { fixed } \\
\text { EHP }\end{array}$ & $\begin{array}{c}\% \\
\text { reduction } \\
\text { in speed } \\
\text { for fixed } \\
\text { EHP } \\
\end{array}$ \\
\hline $10 \%$ Mixed & 23.96 & 21.84 & $8.82 \%$ & 12.02 & 11.11 & $7.58 \%$ & 12.29 & 11.24 & $8.53 \%$ & 13.81 & 12.67 & $8.24 \%$ & 11.92 & 11.24 & $5.71 \%$ & 13.85 & 12.87 & $7.05 \%$ \\
\hline $10 \%$ NS Mixed & 23.80 & 21.35 & $10.31 \%$ & 12.28 & 11.19 & $8.89 \%$ & 11.94 & 10.75 & $9.95 \%$ & 13.94 & 12.59 & $9.67 \%$ & 12.12 & 11.30 & $6.77 \%$ & 14.10 & 12.92 & $8.28 \%$ \\
\hline $10 \% \mathrm{~B}$ & 23.98 & 21.13 & $11.88 \%$ & 11.91 & 10.72 & $9.98 \%$ & 11.82 & 10.50 & $11.18 \%$ & 13.89 & 12.37 & $10.98 \%$ & 12.03 & 11.10 & $7.74 \%$ & 14.06 & 12.73 & $9.41 \%$ \\
\hline $20 \%$ Mixed & 23.93 & 20.67 & $13.65 \%$ & 12.10 & 10.65 & $11.98 \%$ & 12.32 & 10.67 & $13.37 \%$ & 13.79 & 12.00 & $12.98 \%$ & 11.88 & 10.77 & $9.35 \%$ & 13.90 & 12.35 & $11.19 \%$ \\
\hline $20 \%$ NS Mixed & 24.52 & 20.98 & $14.46 \%$ & 11.76 & 10.27 & $12.67 \%$ & 12.47 & 10.71 & $14.16 \%$ & 13.86 & 11.95 & $13.77 \%$ & 12.05 & 10.85 & $9.98 \%$ & 14.07 & 12.40 & $11.88 \%$ \\
\hline $20 \% \mathrm{~B}$ & 24.22 & 20.45 & $15.58 \%$ & 12.41 & 10.73 & $13.57 \%$ & 12.12 & 10.29 & $15.10 \%$ & 13.97 & 11.91 & $14.76 \%$ & 12.14 & 10.83 & $10.76 \%$ & 14.22 & 12.41 & $12.74 \%$ \\
\hline $40 \%$ Mixed & 24.38 & 19.84 & $18.62 \%$ & 12.88 & 10.75 & $16.50 \%$ & 11.75 & 9.62 & $18.16 \%$ & 13.91 & 11.42 & $17.84 \%$ & 11.89 & 10.31 & $13.33 \%$ & 14.10 & 11.92 & $15.48 \%$ \\
\hline $40 \%$ NS Mixed & 23.83 & 19.36 & $18.73 \%$ & 12.54 & 10.45 & $16.71 \%$ & 12.15 & 9.91 & $18.45 \%$ & 13.78 & 11.29 & $18.06 \%$ & 11.89 & 10.28 & $13.54 \%$ & 14.03 & 11.83 & $15.68 \%$ \\
\hline $50 \%$ Mixed & 23.99 & 19.19 & $20.06 \%$ & 12.26 & 10.07 & $17.85 \%$ & 11.77 & 9.45 & $19.68 \%$ & 13.82 & 11.14 & $19.34 \%$ & 11.84 & 10.11 & $14.63 \%$ & 14.06 & 11.69 & $16.82 \%$ \\
\hline $50 \%$ NS Mixed & 24.00 & 19.09 & $20.46 \%$ & 12.67 & 10.35 & $18.34 \%$ & 12.24 & 9.76 & $20.21 \%$ & 13.75 & 11.03 & $19.81 \%$ & 12.16 & 10.38 & $14.66 \%$ & 14.03 & 11.61 & $17.24 \%$ \\
\hline
\end{tabular}




\section{DISCUSSION AND CONCLUSIONS}

An experimental study investigating the effect of barnacle settlement pattern on ship resistance and powering has been presented. The 3D printed artificial surfaces, modelling barnacle fouling, were used similar to that used by Demirel et al. [20]. However, in this study, a chaotic settlement pattern representing the natural settlement was proposed, and the results were compared with the standard settlement.

The flat plates covered with barnacles were towed, and total resistances of plates were measured over a certain range of speed. The frictional resistance values were then calculated.

Finally, the overall drag method of Granville [29] was employed to calculate the roughness functions of the test surfaces, and then the changes in frictional resistance at ship scale were predicted by using Granville's similarity law scaling for the case studies [17]. The increases in frictional resistance and effective power over a different range of ship speeds were illustrated in diagrams. Moreover, based on the assumption of fixed effective power, possible speed reductions due to fouled conditions were calculated for various ship design speeds.

This study revealed that barnacle fouling has a severe effect on ship resistance and powering. An exciting outcome from the results is that the settlement pattern does not affect the frictional resistance and power as much as expected, especially at the ship scale. In addition, findings of the study demonstrated that increased coverage rate minimises the effect of settlement pattern, which means differences in $\mathrm{C}_{\mathrm{F}}$ and $\mathrm{P}_{\mathrm{E}}$ between the natural settlements and standard settlements decrease with the increase in coverage rate.

The range of percentage increases varies from $49.6 \%$ to $153.6 \%$ in $\mathrm{C}_{\mathrm{F}}, 31.9 \%$ to $98.7 \%$ in $\mathrm{P}_{\mathrm{E}}$ for a $230 \mathrm{~m}$ Container ship cruising at the design speed of 24 knots. These values altered to $42.43 \%$ and $133.7 \%$ in $\mathrm{C}_{\mathrm{F}}, 26.7 \%$ and $83.6 \%$ in $\mathrm{P}_{\mathrm{E}}$ for a $270 \mathrm{~m}$ LNG ship at a design speed of 12 knots. These increases were predicted to be $44.1 \%$ to $139.3 \%$ in $\mathrm{C}_{\mathrm{F}}, 30.6 \%$ and $96.8 \%$ in $\mathrm{P}_{\mathrm{E}}$ for $180 \mathrm{~m}$ of Bulk-carrier at 12 knots whereas these values changed to $46.9 \%$ and 149.7 in $\mathrm{C}_{\mathrm{F}}, 29.4 \%$ and $93.9 \%$ in $\mathrm{P}_{\mathrm{E}}$ for $120 \mathrm{~m}$ special purpose vessel at design speed of 14 knots. Finally, the percentage increases in $C_{F}$ and $P_{E}$ ranged from $48.5 \%$ to $153.8 \%$ and $19.2 \%$ to $60.9 \%$ for a $60 \mathrm{~m}$ special purpose vessel at a design speed of 12 knots.

The average difference in $\Delta \mathrm{C}_{\mathrm{F}}$ between standard and natural settlement configurations were predicted to be up to a maximum of $11 \%$ at model scale results. It is observed that this difference decreased with the increase in surface coverage rates. The percentage differences ranged from $0.92 \%$ to $10.53 \%$ in $\Delta \mathrm{C}_{\mathrm{F}}$ and from $0.21 \%$ to $6.7 \%$ in $\Delta \mathrm{P}_{\mathrm{E}}$ due to settlement pattern at full-scale results.

Due to fouling conditions, the percentage speed reductions at fixed effective power were predicted to be in a range from $8.8 \%$ to $20.4 \%$ at a ship speed of 24 knots for $230 \mathrm{~m}$ of Container ship, from $7.5 \%$ to $18.5 \%$ at a ship speed of 12 knots for $270 \mathrm{~m} \mathrm{LNG} \mathrm{carrier} \mathrm{and}$ from $8.5 \%$ to $20.2 \%$ at a ship speed of 12 knots for a $180 \mathrm{~m}$ of Bulk-carrier. These values changed to from $8.2 \%$ to $19.8 \%$ at a ship speed of 12 knots for $120 \mathrm{~m}$ of special purpose vessel, from $5.7 \%$ to $14.6 \%$ at a ship speed of 12 knots for $60 \mathrm{~m}$ of special-purpose vessel and from $7 \%$ to $17.2 \%$ at a ship speed of 14 knots for $250 \mathrm{~m}$ tanker. 
The proposed diagrams are suitable for predicting the increases in frictional resistance, effective power and hence fuel consumption due to fouling conditions. In addition to that, the presented possible speed reductions due to given fouling conditions can be used as a reference source for ship operators. Therefore, the authors hope that this research may support decision-makers by helping them to decide on the most effective ship hull cleaning and maintenance schedule.

Future works should concentrate on the effect of slime, algae, weed and other types of calcareous fouling on ship resistance and power as well as considering settlement parameters in these fouling conditions. Moreover, similar research can be implemented on ship propeller and open water tests to understand the effect of biofouling on the efficiency of propellers [37]. This method is also promising and useful on the rudder in order to measure the effect of fouling on lift coefficient $\left(\mathrm{C}_{\mathrm{L}}\right)$ and drag coefficient $\left(\mathrm{C}_{\mathrm{D}}\right)$ of rudder's NACA profile and hence the difference in manoeuvring performance.

\section{NOMENCLATURE}

$C_{F_{R}} \quad$ frictional resistance coefficient in rough condition

$C_{F_{S}} \quad$ frictional resistance coefficient in smooth condition

$C_{R_{R}} \quad$ residuary resistance coefficient in rough condition

$C_{R_{S}} \quad$ residuary resistance coefficient in smooth condition

$C_{T_{R}} \quad$ total resistance coefficient in rough condition

$C_{T_{S}} \quad$ total resistance coefficient in smooth condition

$\Delta C_{F} \quad$ added resistance coefficient due to surface roughness

$\triangle P_{E} \quad$ increase in effective power due to surface roughness

$\mathrm{CA}$ coverage area

$\mathrm{C}_{\mathrm{D}} \quad$ drag coefficient

$\mathrm{C}_{\mathrm{F}} \quad$ frictional resistance coefficient

CFD computational fluid dynamics

$C_{k} \quad$ roughness coefficient

$\mathrm{C}_{\mathrm{L}} \quad$ lift coefficient

$\mathrm{C}_{\mathrm{R}}$ residuary resistance coefficient

$\mathrm{C}_{\mathrm{T}} \quad$ total drag coefficient

$h$ the highest roughness height

$k \quad$ roughness length scale

$k^{+} \quad$ roughness Reynolds number

$k_{G} \quad$ experimentally obtained equivalent roughness length scale

$\mathrm{k}_{\mathrm{s}} \quad$ equivalent sand roughness

NS natural settlement

$\mathrm{P}_{\mathrm{E}} \quad$ effective power

$\mathrm{Re} \quad$ Reynolds number

$S \quad$ wetted surface area

SC surface coverage (\%) 


$\begin{array}{ll}V & \text { speed } \\ \Delta U^{+^{\prime}} & \text { the slope of roughness function } \\ \Delta U^{+} & \text {roughness function } \\ \kappa & \text { von Karman constant } \\ \rho & \text { density of water }\end{array}$

\section{ACKNOWLEDGEMENTS}

This research did not receive any specific grant from funding agencies in the public, commercial, or not-for-profit sectors.

\section{DISCLOSURE STATEMENT}

No potential conflict of interest was reported by the authors.

\section{REFERENCES}

[1] Townsin R. The ship hull fouling penalty. Biofouling. 2003;19:9-15.

[2] Schultz MP. Effects of coating roughness and biofouling on ship resistance and powering. Biofouling. 2007;23:331-41.

[3] Tezdogan T, Demirel YK. An overview of marine corrosion protection with a focus on cathodic protection and coatings. Brodogradnja: Teorija i praksa brodogradnje i pomorske tehnike. 2014;65:49-59.

[4] McEntee W. VARIATION OF FRICTIONAL RESISTANCE OF SHJPS WITH CONDITION OF WETTED SURFACE. Journal of the American Society for Naval Engineers. 1916;28:311-4.

[5] Izubuchi T. Effect of fouling of ship's bottom on the resistance of ships. Journal of Zosen Kiokai. 1934;1934:57-100.

[6] Kempf G. On the effect of roughness on the resistance of ships. Trans INA. 1937; 79:109-19.

[7] Conn JFC, Lackenby H, Walker WP. Resistance experiments on the Lucy Ashton. Trans INA. 1953;95:350 - 436 .

[8] Watanabe S, Nagamatsu N, Yokoo K, Kawakami Y. The augmentation in frictional resistance due to slime. . J Kansai Soc Nav Arc. 1969;131:45-53.

[9] Loeb G, Laster D, Gracik T. The influence of microbial fouling films on hydrodynamic drag of rotating discs. In: JD C, R T, editors. Marine biodeterioration: an interdisciplinary study. Annapolis (MD): Naval Institute Press; 1984. p. 88-94.

[10] Lewthwaite J, Molland A, Thomas K. An investigation into the variation of ship skin frictional resistance with fouling. Royal Institution of Naval Architects Transactions. $1985 ; 127$.

[11] Haslbeck EG, Bohlander GS. Microbial biofilm effects on drag-lab and field. Naval surface warfare center carderock div annapolis MD; 1992.

[12] Schultz M, Swain G. The effect of biofilms on turbulent boundary layers. Journal of Fluids engineering. 1999;121:44-51.

[13] Schultz MP. Turbulent boundary layers on surfaces covered with filamentous algae. Journal of fluids engineering. 2000;122:357-63. 
[14] Holm E, Schultz M, Haslbeck E, Talbott W, Field A. Evaluation of hydrodynamic drag on experimental fouling-release surfaces, using rotating disks. Biofouling. 2004;20:219-26.

[15] Schultz MP. Frictional resistance of antifouling coating systems. Transactions of the ASME-I-Journal of Fluids Engineering. 2004;126:1039-47.

[16] D3623 A. Standard Test Method for Testing Antifouling Panels in Shallow Submergence. 1994.

[17] Granville PS. The Frictional Resistance and Turbulent Boundary Layer of Rough Surfaces. SNAME-JSR-1958-2-4-52. 1958;2:52-74.

[18] Swain GW, Kovach B, Touzot A, Casse F, Kavanagh CJ. Measuring the Performance of Today's Antifouling Coatings. Journal of Ship Production. 2007;23:164-70.

[19] Lindholdt A, Dam-Johansen K, Olsen SM, Yebra DM, Kiil S. Effects of biofouling development on drag forces of hull coatings for ocean-going ships: a review. Journal of Coatings Technology and Research. 2015;12:415-44.

[20] Demirel YK, Uzun D, Zhang Y, Fang HC, Day AH, Turan O. Effect of barnacle fouling on ship resistance and powering. Biofouling. 2017;33:819-34.

[21] Demirel YK, Khorasanchi M, Turan O, Incecik A. On the importance of antifouling coatings regarding ship resistance and powering. 3rd International Conference on Technologies, Operations, Logistics and Modelling for Low Carbon Shipping2013.

[22] Schultz M, Bendick J, Holm E, Hertel W. Economic impact of biofouling on a naval surface ship. Biofouling. 2011;27:87-98.

[23] Turan O, Demirel YK, Day S, Tezdogan T. Experimental determination of added hydrodynamic resistance caused by marine biofouling on ships. Transportation Research Procedia. 2016;14:1649-58.

[24] Demirel YK. Modelling the roughness effects of marine coatings and biofouling on ship frictional resistance: University of Strathclyde; 2015.

[25] Uzun D, Zhang Y, Demirel YK, Turan O. Experimental determination of added resistance due to barnacle fouling on ships by using 3D printed barnacles. 2017.

[26] Song S, Demirel YK, Atlar M. An investigation into the effect of biofouling on the ship hydrodynamic characteristics using CFD. Ocean Engineering. 2019;175:122-37.

[27] International A. D6990-05 Standard Practice for Evaluating Biofouling Resistance and Physical Performance of Marine Coating Systems. West Conshohocken, PA2011.

[28] Schoenherr KE. Resistance of flat surfaces moving through a fluid, by Karl E. Schoenherr, a dissertation submitted ... to the Johns Hopkins University ... for the degree of doctor of engineering, 1932. [S.1.]: [s.n.]; 1932.

[29] Granville PS. Three indirect methods for the drag characterization of arbitrarily rough surfaces on flat plates. Proceedings of the Twenty-first American Towing Tank Conference: National Academies; 1987. p. 117.

[30] Ioselevich V, Pilipenko V. Logarithmic velocity profile for flow of a weak polymer solution near a rough surface. Soviet Physics Doklady1974. p. 790.

[31] Grigson C. Drag losses of new ships caused by hull finish. SNAME-JSR-1958-2-4-52. 1992;36:182-96.

[32] Nikuradse J. Laws of flow in rough pipes NACA Technical Memorandum (1292). 1933.

[33] Demirel YK, Turan O, Incecik A. Predicting the effect of biofouling on ship resistance using CFD. Applied Ocean Research. 2017;62:100-18.

[34] Schultz MP, Flack KA. The rough-wall turbulent boundary layer from the hydraulically smooth to the fully rough regime. Journal of Fluid Mechanics. 2007;580:381-405.

[35] ITTC. Uncertainty analysis, example for resistance test. ITTC recommended procedures and guidelines 2002 .

[36] Demirel YK, Song S, Turan O, Incecik A. Practical added resistance diagrams to predict fouling impact on ship performance. Ocean Engineering. 2019;186:106112. 
[37] Owen D, Demirel YK, Oguz E, Tezdogan T, Incecik A. Investigating the effect of biofouling on propeller characteristics using CFD. Ocean Engineering. 2018;159:505-16.

\section{APPENDICES}

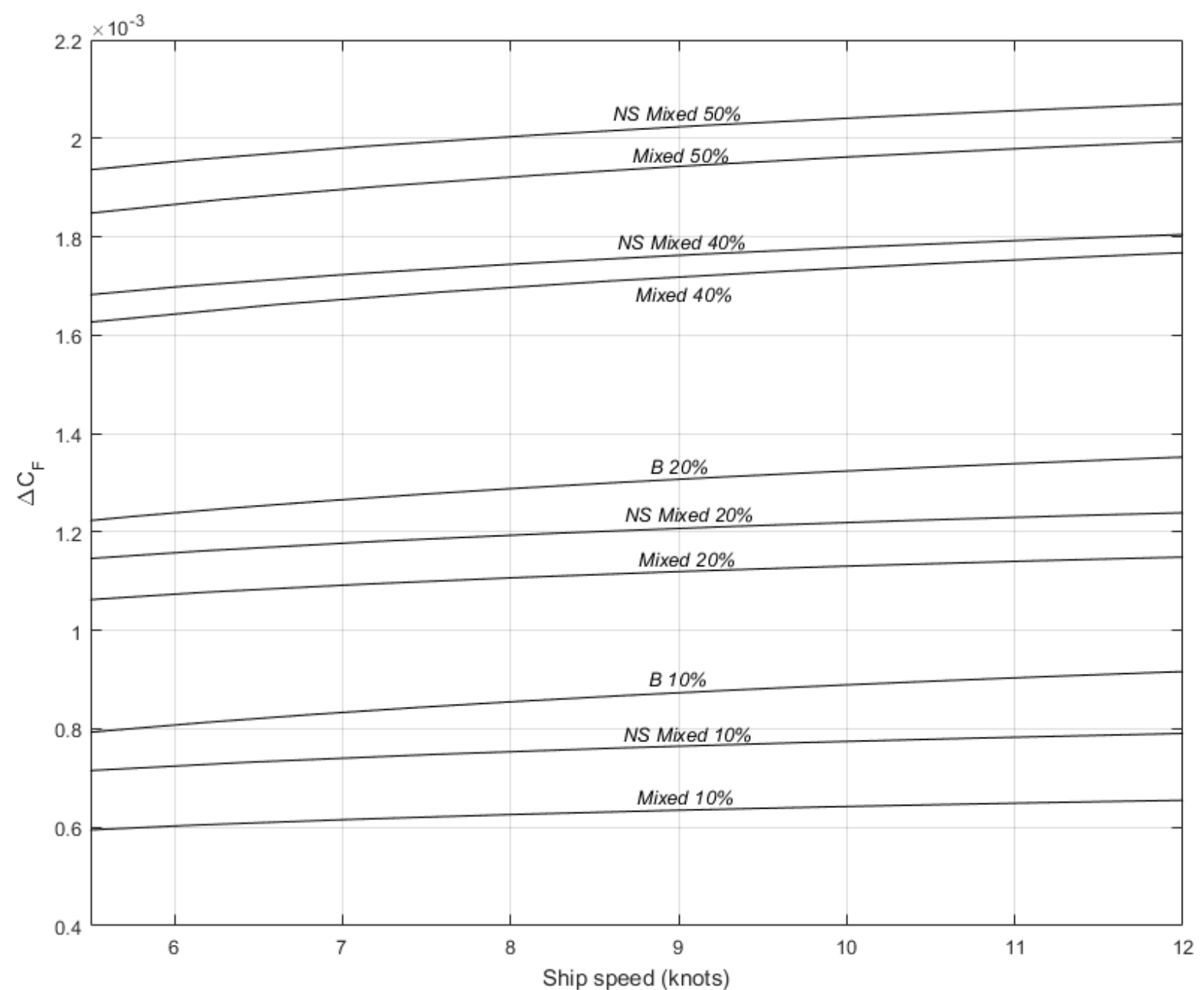

Fig. A1. Added frictional resistance diagram for a $180 \mathrm{~m}$ Bulk carrier ship with different barnacle fouling conditions 


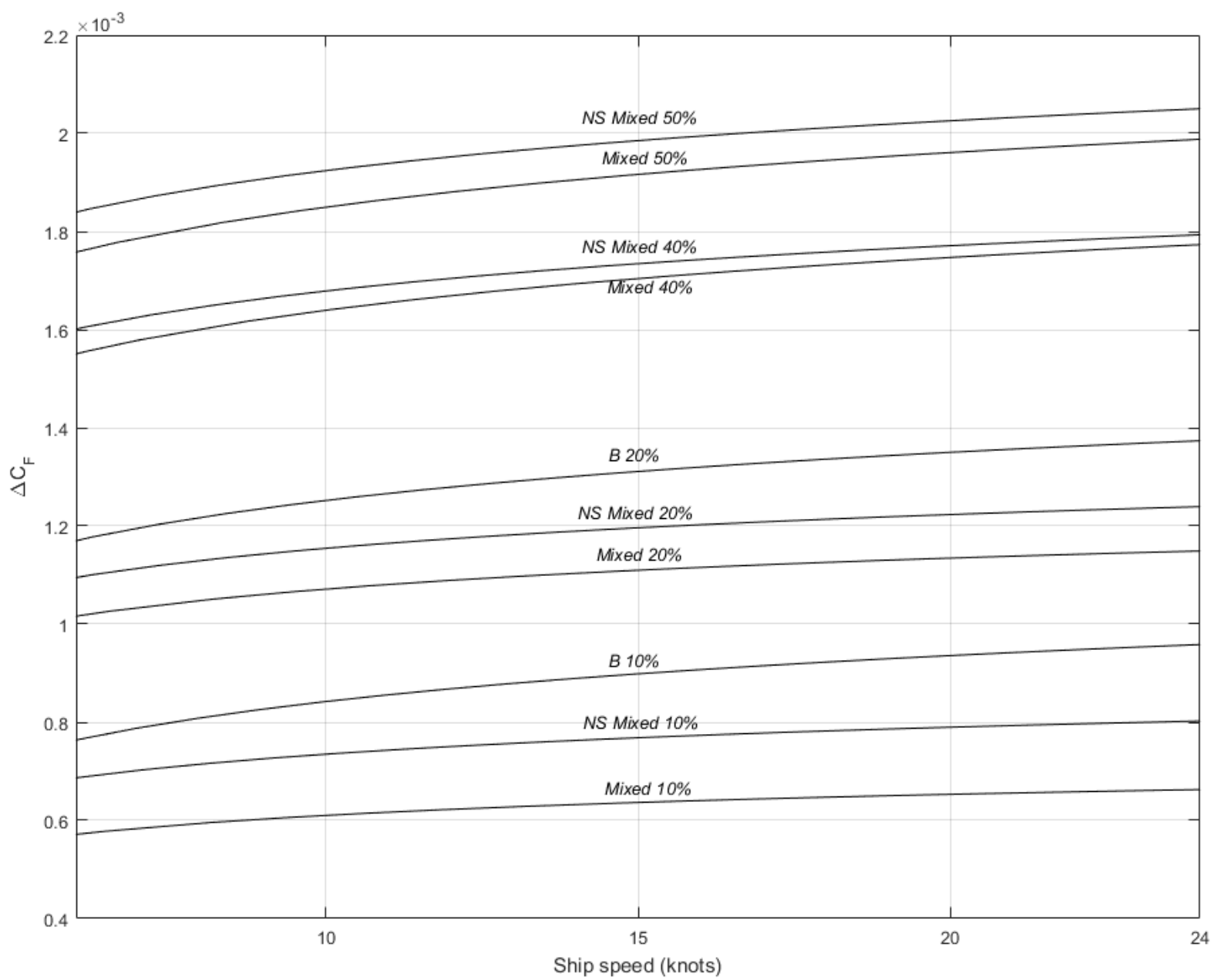

Fig. A2. Added frictional resistance diagram for a $230 \mathrm{~m}$ Container ship with different barnacle fouling conditions 


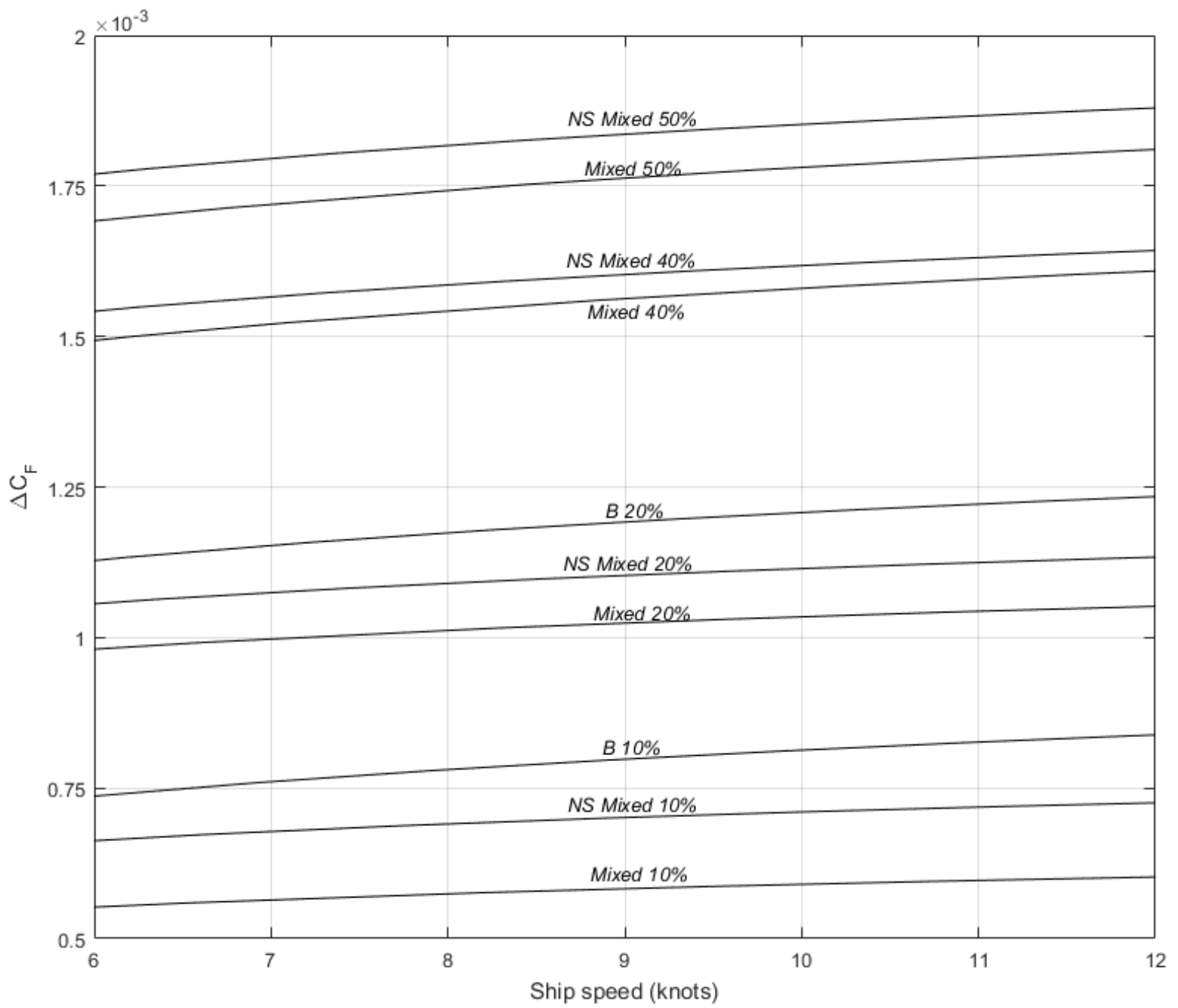

Fig. A3. Added frictional resistance diagram for a 270m LNG ship with different barnacle fouling conditions 


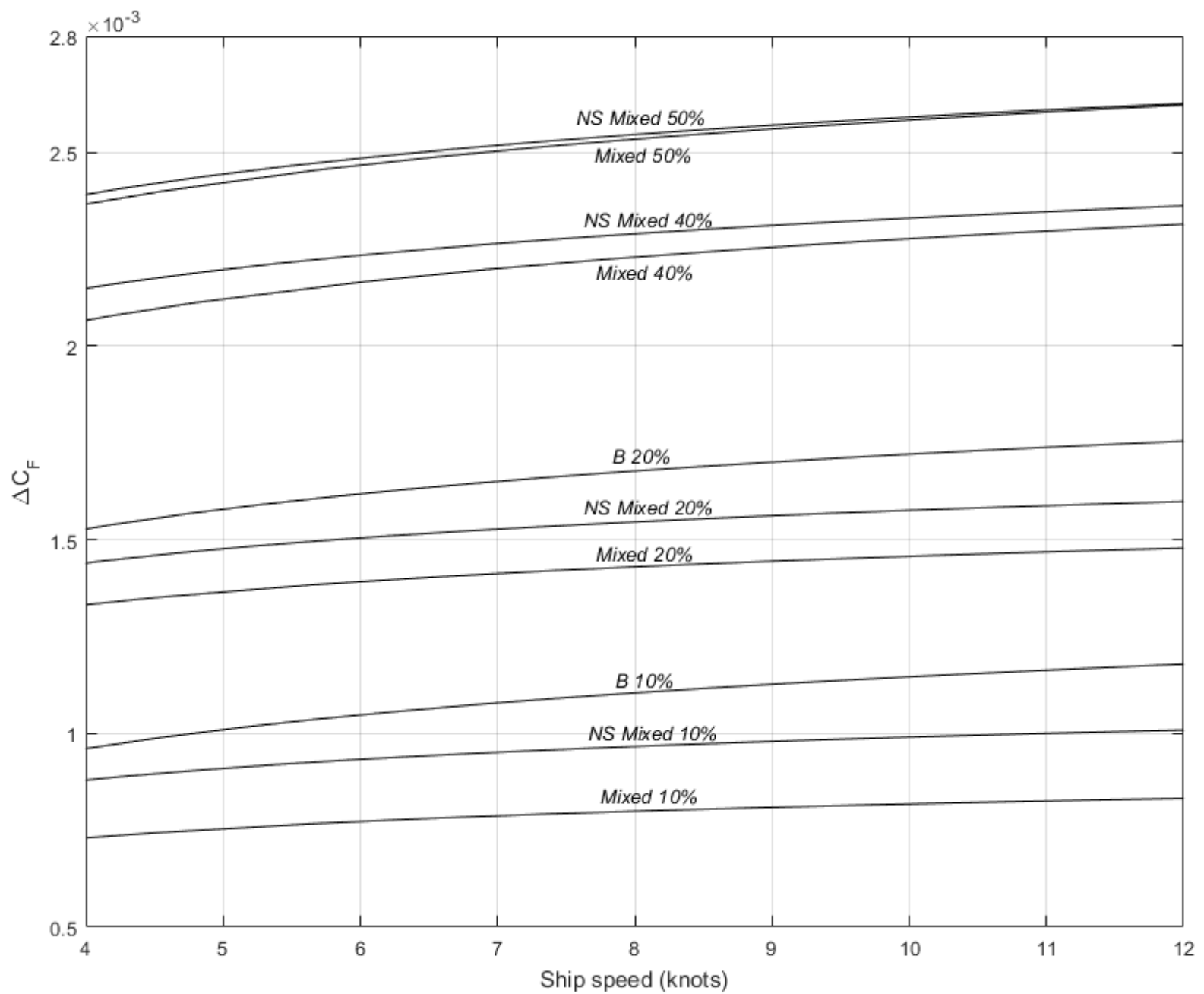

Fig. A4. Added frictional resistance diagram for a $60 \mathrm{~m}$ Special purpose vessel with different barnacle fouling conditions 


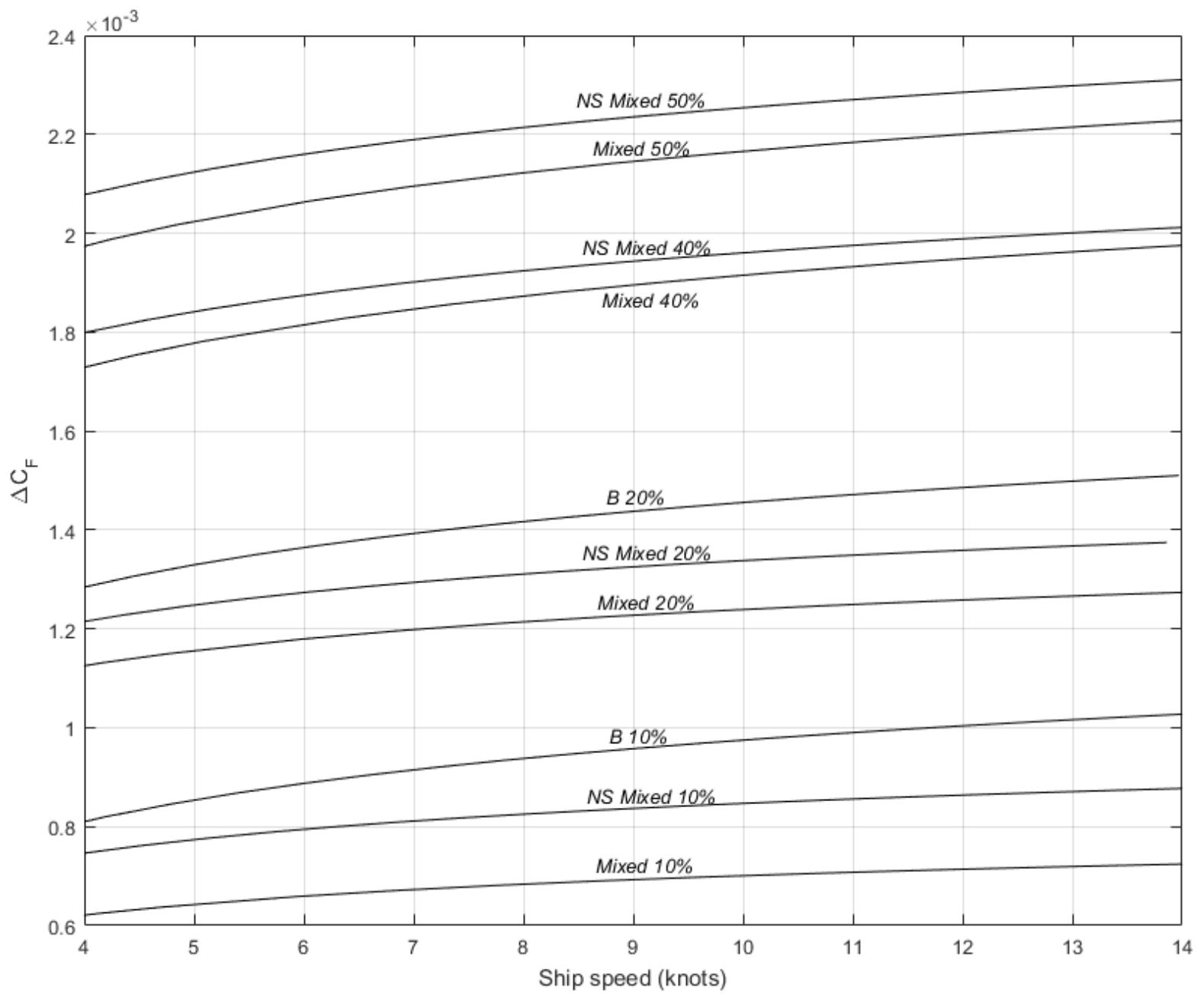

Fig. A5. Added frictional resistance diagram for a $120 \mathrm{~m}$ Special purpose vessel with different barnacle fouling conditions 